\title{
Arabidopsis DNA polymerase lambda mutant is mildly sensitive to DNA double strand breaks but defective in integration of a transgene
}

\section{OPEN ACCESS}

Edited by:

Ayako N. Sakamoto,

Japan Atomic Energy Agency, Japan

Reviewed by:

Charles I. White

Centre National de la Recherche

Scientifique, France

Katarzyna Bebenek,

National Institute of Environmental Health Sciences/National Institutes of Health, USA

Yuichiro Yokota,

Japan Atomic Energy Agency, Japan

*Correspondence:

Anne B. Britt,

Department of Plant Biology, University of California at Davis, One Shields Avenue, Davis,

CA 95616, USA

abbritt@ucdavis.edu

${ }^{\dagger}$ Present Address:

Tomoyuki Furukawa

Breeding Research Department Mikado Kyowa Seed Co Ltd., Otaki,

Japan

Specialty section

This article was submitted to Plant Physiology, a section of the journal Frontiers in Plant Science

Received: 01 March 2015 Accepted: 05 May 2015 Published: 27 May 2015

Citation:

Furukawa T, Angelis $K J$ and Britt $A B$ (2015) Arabidopsis DNA polymerase lambda mutant is mildly sensitive to

DNA double strand breaks but defective in integration of a transgene.

Front. Plant Sci. 6:357.

doi: 10.3389/fpls.2015.00357
Tomoyuki Furukawa ${ }^{1 \dagger}$, Karel J. Angelis ${ }^{2}$ and Anne B. Britt ${ }^{1 *}$

${ }^{1}$ Department of Plant Biology, University of California at Davis, Davis, CA, USA, ${ }^{2}$ DNA Repair Lab, Institute of Experimental Botany of the Academy of Sciences of the Czech Republic, Praha, Czech Republic

The DNA double-strand break (DSB) is a critical type of damage, and can be induced by both endogenous sources (e.g., errors of oxidative metabolism, transposable elements, programmed meiotic breaks, or perturbation of the DNA replication fork) and exogenous sources (e.g., ionizing radiation or radiomimetic chemicals). Although higher plants, like mammals, are thought to preferentially repair DSBs via nonhomologous end joining (NHEJ), much remains unclear about plant DSB repair pathways. Our reverse genetic approach suggests that DNA polymerase $\lambda$ is involved in DSB repair in Arabidopsis. The Arabidopsis T-DNA insertion mutant (atpol $\lambda-1)$ displayed sensitivity to both gamma-irradiation and treatment with radiomimetic reagents, but not to other DNA damaging treatments. The atpol $\lambda-1$ mutant showed a moderate sensitivity to DSBs, while Arabidopsis Ku70 and DNA ligase 4 mutants (atku70-3 and atlig4-2), both of which play critical roles in NHEJ, exhibited a hypersensitivity to these treatments. The atpol $\lambda$-1/atlig4-2 double mutant exhibited a higher sensitivity to DSBs than each single mutant, but the atku70/atpol $\lambda-1$ showed similar sensitivity to the atku70-3 mutant. We showed that transcription of the DNA ligase 1, DNA ligase 6, and Wee1 genes was quickly induced by BLM in several NHEJ deficient mutants in contrast to wild-type. Finally, the T-DNA transformation efficiency dropped in NHEJ deficient mutants and the lowest transformation efficiency was scored in the atpol $\lambda$-1/atlig4-2 double mutant. These results imply that AtPol $\lambda$ is involved in both DSB repair and DNA damage response pathway.

Keywords: DNA polymerase, DNA repair, Non homologous end joining, DNA damage response, double strand breaks

\section{Introduction}

The 3R mechanisms (DNA replication, repair, and recombination) are key machineries for all living organisms. DNA-dependent DNA polymerases play critical roles in $3 \mathrm{R}$ mechanisms. To date, at least 13 types of DNA polymerases (Pol $\alpha, \beta, \gamma, \delta, \varepsilon, \zeta, \eta, \theta, \iota, \kappa, \lambda, \mu$, and $\nu$ ) and two polymerase homologs, terminal deoxyribonucleotidyl transferases (TdT), and REV1, have been found in the human genome. Based on amino acid sequence homology, DNA polymerases are classified into four different polymerase families (A, B, X, and Y). DNA polymerase $\lambda$ belongs to the Pol X-family 
along with three other non-replicative mammalian DNA polymerases (Pol $\beta$, Pol $\mu$, and TdT). The structure of the Pol $\lambda$ protein consists of three functional domains: a BRCT (BRCA1 C-terminus) domain at the N-terminus, a DNA binding domain in the central region, and a DNA polymerization domain at the C-terminus, respectively. Biochemical studies have revealed that the human Pol $\lambda$ protein has three enzymatic activities: DNA polymerase activity, TdT activity, and $5^{\prime}$-Deoxyribose5 -phosphate (dRP lyase) activity. Although the human Pol $\lambda$ protein is able to incorporate multiple nucleotides during the in vitro reaction, its processivity is low compared to replicativetype DNA polymerases ( $\mathrm{Pol} \alpha, \delta, \varepsilon)$. These enzymatic activities suggest that Pol $\lambda$ participates in two DNA repair pathways; base excision repair and NHEJ (Braithwaite et al., 2005a,b, 2010; Garcia-Diaz et al., 2005; Nick McElhinny et al., 2005). Both DNA polymerase and dRP lyase activities are required for short-patch base excision repair (spBER). Physical interaction of Pol $\lambda$ with the XRCC4/Lig4 complex implies that Pol $\lambda$ also participates in alignment-based gap filling during NHEJ (Fan and Wu, 2004; Lee et al., 2004; Capp et al., 2006).

In contrast to a long history of study of mammalian and yeast DNA polymerases, much remains unclear regarding the plant DNA polymerases. A recent advance of plant genome projects has revealed that plant genomes encode homologs for 10 DNA polymerases (Pol $\alpha, \delta, \varepsilon, \zeta, \eta, \theta, \kappa, \lambda, \sigma$, and $\nu$ ) (Yokoi et al., 1997; Uchiyama et al., 2002, 2004; Sakamoto et al., 2003; Garcia-Ortiz et al., 2004; Takahashi et al., 2005; Inagaki et al., 2006; Anderson et al., 2008) and two plastid-specific Pol I-like DNA polymerases (Kimura et al., 2002; Mori et al., 2005; Ono et al., 2007). Despite the fact that Pol $\lambda$ is widely conserved in the genome regardless of higher (Oryza sativa as monocots and Arabidopsis as dicots) and lower (Chlamydomonas reinhardtii, Uchiyama et al., 2009) plants, no other Pol X-family homolog genes have been identified in plant genomes. These observations strongly indicate that plants have only Pol $\lambda$ among Pol X-family members.

The function of plant Pol $\lambda$ has been studied using rice and Arabidopsis as model plants (Garcia-Diaz et al., 2000; Uchiyama et al., 2004; Amoroso et al., 2011; Roy et al., 2011). Like human Pol $\lambda$, rice Pol $\lambda$ protein (OsPol $\lambda$ ) possesses DNA polymerase activity, weak TdT activity, and dRP lyase activity and this polymerase activity is activated by rice PCNA (proliferating cell nuclear antigen) protein. Expression analysis of $\mathrm{OsPol} \lambda$ transcripts suggests that it functions in DNA replication and/or repair in both meristematic and meiotic tissues (Uchiyama et al., 2004). The physical partner of plant Pol $\lambda$ protein has been identified by yeast two-hybrid or pull-down assay. OsPol $\lambda$ is able to bind with rice exonuclease-1, but not with rice XRCC1 (Furukawa et al., 2008; Uchiyama et al., 2008). Physical interaction of AtPol $\lambda$ with AtPCNA2 stimulates its fidelity and efficiency in translesion synthesis (Amoroso et al., 2011). The role of Arabidopsis Pol $\lambda($ AtPol $\lambda)$ in DNA repair has been recently reported. UV-B radiation induces the expression of AtPol $\lambda$, and three AtPol $\lambda$ mutants (atpol $\lambda-1$, atpol $\lambda-2$, and atpol $\lambda$ 3) exhibit sensitivity to UV-B and MMC (Roy et al., 2011, 2013). The AtPol $\lambda$ mutants show increased sensitivity when exposed to high salinity and MMC treatment. AtPol $\lambda$ is able to interact with AtLig4 and AtXRCC4 through its BRCT domain

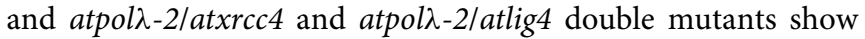
delayed repair of salinity-induced DSBs (Roy et al., 2013). These findings suggest that plant Pol $\lambda$ plays a role in various DNA repair pathways. Recent studies have indicated a role for Pol $\lambda$ in the repair of transposable element excision sites, suggesting involvement in the repair of DSBs (Huefner et al., 2011).

We report here that Arabidopsis DNA polymerase $\lambda$ (AtPol $\lambda$ ) is employed in DSB repair in response to clastogenic agents and is involved in T-DNA integration. In addition, our results imply that AtPol $\lambda$, in concert with AtLig1 and AtLig6, may participate in the Lig4-independent alternative NHEJ pathway.

\section{Materials and Methods}

\section{Isolation of Mutants}

We used the Arabidopsis thaliana parental strain ecotype Col (Columbia) in this study. The atpold-1 (SALK_75391C) and atku70-3 (SALK_123114C) mutants were identified using the Salk SIGnAL Web site (http://signal.salk.edu/), and their seeds were obtained from the ABRC. The atlig4-2 line has been previously described (Friesner and Britt, 2003). The atpol $\lambda-1$ and atku70 homozygous mutants were identified by genotyping PCR with gene-specific primer sets. To analyze the atpol $\lambda-1$ transcript, PCR with three different primer sets (pol $\lambda-1 \mathrm{AF}+$ pol $\lambda-1 \mathrm{AR}, \operatorname{pol} \lambda-1 \mathrm{BF}+\operatorname{pol} \lambda-1 \mathrm{BR}$, and pol $\lambda-1 \mathrm{CF}+\operatorname{pol} \lambda-1 \mathrm{CR})$ were performed with cDNA synthesized from atpol $\lambda-1$ total RNA. The upstream region of the atpol $\lambda-1$ transcript containing a RB border region was amplified by PCR with the pol $\lambda-1 \mathrm{BF}+$ $\mathrm{RBcl}$ primer set and the amplified PCR product was sequenced using the RBb1 primer. The downstream region containing a LB border was amplified with the $\mathrm{LBb} 1+\operatorname{pol} \lambda-1 \mathrm{CR}$ primer set and the amplified product was sequenced using the LBb1 primer. The atpol $\lambda-1$ line was crossed with either atku70-3 or atlig4-2 line to make double mutants. Homozygous F2 offsprings were screened by genotyping PCR with gene specific primer sets; pol $\lambda-1 \mathrm{BF}$, pol $\lambda-1 \mathrm{BR}, \mathrm{ku} 70 \mathrm{~F}, \mathrm{ku} 70 \mathrm{R}$ and T-DNA specific primer LBb1 for atku70-3/atpol $\lambda-1$ double mutants and pol $\lambda$ $1 \mathrm{BF}$, pol $\lambda-1 \mathrm{BR}$, lig4-2B, lig4-2C, and LBb1 for atpol $\lambda-1 /$ atlig4-2 double mutants. Primers sequences were shown in Supplemental Table S1.

\section{Growth of Arabidopsis}

Seeds in microcentifuge tubes were surface-sterilized in an airtight container filled with chlorine gas for $2 \mathrm{~h}$. Chlorine gas was produced by mixing $30 \mathrm{ml}$ of bleach and $5 \mathrm{ml}$ of hydrochloric acid. Following degassing of chlorine gas in a fume hood, sterilized seeds were imbibed in water for 2 days at $4^{\circ} \mathrm{C}$. The sterilized seeds were then sown on solid $1 \times$ Murashige and Skoog (MS, Sigma-Aldrich, St. Louis, MO, USA) with $\mathrm{pH}$ adjusted to 5.8 using $1 \mathrm{~N} \mathrm{KOH}$ containing $0.8 \%$ phytoagar (PlantMedia, Dublin, OH, USA) plates or on soil, and grown in a climate chamber under cool-white lamps at an intensity of $100-150 \mu \mathrm{mol} \mathrm{m}{ }^{-2} \mathrm{~s}^{-1}$ with a cycle of $16 \mathrm{~h}$ day $/ 8 \mathrm{~h}$ night at $20^{\circ} \mathrm{C}$.

\section{DNA Damaging Treatments}

For sensitivity tests to DNA damaging reagents such as methyl methanesulfonate (MMS, Fisher Scientific, Pittsburgh, PA, USA), 
mitomycin C (MMC, Fisher), methyl viologen (MV, Fisher), and bleomycin (BLM, Bleocin inj., Euro Nippon Kayaku GmbH, Germany), chlorine gas-sterilized seeds were sown on solid MSagar plates supplemented with each chemical. Seeds were grown for 7 days in a growth chamber under the normal growth condition as shown above. For the root-swollen assay, the 3 dayold seedlings were transferred to MS-agar plates containing 0.1 or $0.25 \mu \mathrm{g} \mathrm{mL} \mathrm{m}^{-1}$ bleomycin and grown in a growth chamber under the normal condition. Ultraviolet B (UV-B) irradiation was performed according to Jiang et al. (1997). Sterilized seeds were planted on solid $1 \times$ MS medium and grown with the plate oriented vertically for 3 days as described above. Seedlings were irradiated with UV-B in the absence of visible light using a UV-transilluminator (Fisher) filtered with $0.005 \mathrm{ml}$ cellulose acetate membrane, with a flux rate of $5.5 \mathrm{~mW} \mathrm{~cm}^{-2}$. The UVB irradiated plates were rotated by $90^{\circ}$, then were cultivated for two more days under orange light to prevent photoreactivation. To investigate sensitivity of mutants to $\gamma$-irradiation, chlorine gas-sterilized seeds in water were $\gamma$-irradiated at $0,40,60,80$, and $100 \mathrm{~Gy}\left(6.43 \mathrm{~Gy} \mathrm{~min}^{-1}\right)$ from a ${ }^{137} \mathrm{Cs}$ source (Institute of Toxicology and Environmental Health, University of California, Davis). Gamma-irradiated seeds were sown on soil or MS-agar plates and grown in a growth chamber as described above.

\section{Gamma-Irradiation and Detection of Cell Death in Irradiated Arabidopsis Plants}

Observation of cell death in gamma-irradiated Arabidopsis roots were performed as described in Furukawa et al. (2010). Briefly, 5 day-old seedlings on MS-agar plates were $\gamma$-irradiated to a final dose of 20 Gy (6.43 Gy $\mathrm{min}^{-1}$ ). Dead cells were visualized by staining of roots with $5 \mu \mathrm{g} \mathrm{mL}^{-1}$ propidium iodide (PI, SigmaAldrich) and were observed using a Leica TSC SP2 confocal microscope.

\section{Quantitative RT-PCR}

Prior to treatment, 5 day-old seedlings were gently transferred from agar to MS liquid medium $( \pm 30 \mu \mathrm{g} \mathrm{mL}-1$ bleomycin in $5 \mathrm{~cm}$ petri plates. The bleomycin treatment time for the expression analysis of DDR genes was $1.5 \mathrm{~h}$, while that of DNA repair genes was $1 \mathrm{~h}$. Treated seedlings were thoroughly rinsed in sterilized water and placed on solid MS plates. Seedlings were collected at each time point after wash. Mock seedlings were treated with liquid MS medium.

Total RNA was extracted from $100 \mathrm{mg}$ of untreated, treated and recovered Arabidopsis seedlings collected using the RNeasy kit (Qiagen, Hilden, Germany) according to the manufacturer's protocol. The cDNAs from $1 \mu \mathrm{g}$ of total RNA were synthesized using iScript cDNA Synthesis kit (Bio-Rad, Hercules, USA) with the help of oligo (dT) blend and random hexamer primers in a $20 \mu \mathrm{l}$ reaction according to supplied protocol. One microliter of heat denaturated cDNA reaction mixture was used for quantitative RT-PCR assay in $20 \mu \mathrm{l}$ reaction volume using iTaq SYBR Green Supermix with ROX master mix (Bio-Rad) with the following primers at final concentration of $500 \mathrm{nM}$.

PCR amplification was carried with LightCycler 480 (Roche, Basel, Switzerland) or MX 3005P cycler (Stratagene, La Jolla, USA). For the reaction with LightCycler 480, an initial denaturation step was for $95^{\circ} \mathrm{C}, 5 \mathrm{~min}$ and subsequent 45 cycles of PCR amplification proceeded as follows: denaturation $20 \mathrm{~s}$ at $95^{\circ} \mathrm{C}$; annealing $20 \mathrm{~s}$ at $59^{\circ} \mathrm{C}$; extension $30 \mathrm{~s}$ at $72^{\circ} \mathrm{C}$. For the reaction with $\mathrm{MX} 3005 \mathrm{P}$ cycler, an initial denaturation step was for $95^{\circ} \mathrm{C}, 3 \mathrm{~min}$ and subsequent 40 cycles of PCR amplification proceeded as follows: denaturation $15 \mathrm{~s}$ at $95^{\circ} \mathrm{C}$; annealing $40 \mathrm{~s}$ at $55^{\circ} \mathrm{C}$; extension $40 \mathrm{~s}$ at $72^{\circ} \mathrm{C}$. After amplification, all fluorescence data were analyzed by the supplied software and normalized against AtUBQ10 and AtActin2, or AtROC3 reference gene transcripts. Sequences of primers used for qRT-PCR were listed in Supplemental Table S1.

\section{Plant Transformation and Observation of Fluorescent Seeds}

The pFLUAR101 fluorescent binary vector (Stuitje et al., 2003) was used to calculate transformation efficiency and transformation of Arabidopsis plants was performed by the Agrobacterium-mediated floral dip method. All siliques, flowers, and buds whose stage was later than stage 12 were trimmed from plants 1 day before transformation. The pFLAR101 vector was transformed into Agrobacterium tumefaciens strain GV3101 by electroporation. Agrobacterium transformant cells were cultured in liquid LB medium supplemented with kanamycin overnight at $30^{\circ} \mathrm{C}$ to reach stationary phase. Following centrifugation, the Agrobacterium cells were diluted to an OD600 of 1.8 with 5\% sucrose solution. Silwet L-77 was added to a final concentration of $0.02 \%$ immediately before dipping. Second trimming was carried out 10 days after dipping to hold 12 siliques seeded from young buds that escaped from first trimming per brunch, and thereafter trimmed bolts were bagged in a glassine paper. Seeds were harvested 3 weeks after second trimming by collecting them in each glassine paper. Transformant seeds expressing fluorescence were screened by the Zeiss SteREO Discovery V12 microscope with a fluorescent filter for DsRED. The number of $\mathrm{T}_{0}$ plants, harvested $\mathrm{T}_{1}$ seeds, $\mathrm{T}_{1}$ seeds expressing DsRED fluorescence, and each plant's transformation efficiency over three trials are described in Supplementary Table S3.

\section{Statistical Analysis}

Experimental results were examined using either $t$-test or OneWay ANOVA (analysis of variance) depending the number of samples. The post-hoc test (Tukey's HSD) was also used to find which means were significantly different. A $P$-value less than $0.05\left({ }^{*} P<0.05\right)$ and $0.01\left({ }^{* *} P<0.01\right)$ was considered significant.

\section{Results}

\section{Identification of the Arabidopsis Pol $\lambda$ Mutant}

We took a reverse genetic approach in order to examine the in vivo function of AtPol $\lambda$. The Salk T-DNA insertion collection was searched using the amino acid sequence of the rice Pol $\lambda$ protein (GenBank Accession: BAD18976) as a template and the SALK_075391C line was found as a homozygous mutant carrying the T-DNA insertion in the AtPol $\lambda$ gene (gene ID: Atlg10520). Sequence analysis of the flanking regions of T-DNA revealed that the T-DNA was inserted in ninth intron of the AtPol $\lambda$ gene 


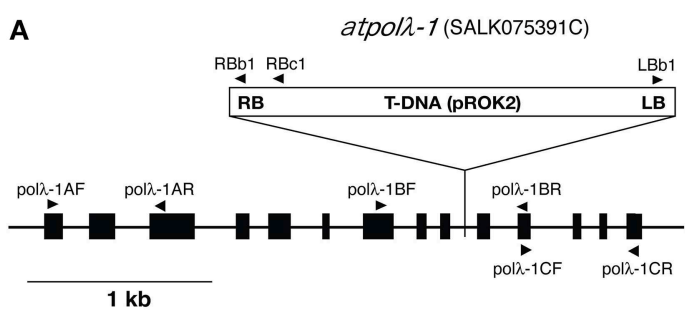

B

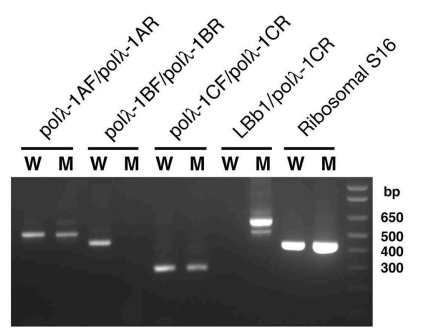

FIGURE 1 | Structure of DNA polymerase $\lambda$ gene in the atpo/ $\lambda-1$ mutant. (A) Schematic structure of the AtPo/ $\lambda$ gene and its T-DNA insertion. Arrowheads represent gene-specific primers used for PCR. RB, T-DNA right border; LB, T-DNA left border. (B) Semiquantitative RT-PCR on different regions of the AtPol $\lambda$ gene. Primer pairs used for $\mathrm{RT}$ T-PCR were $[\mathrm{A} F \mathrm{FW}+\mathrm{A}$ Rev], [B Fw + B Rev], [C Fw + C Rev], and [LBb1 + C Rev]. The Ribosomal

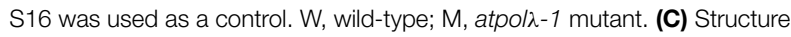

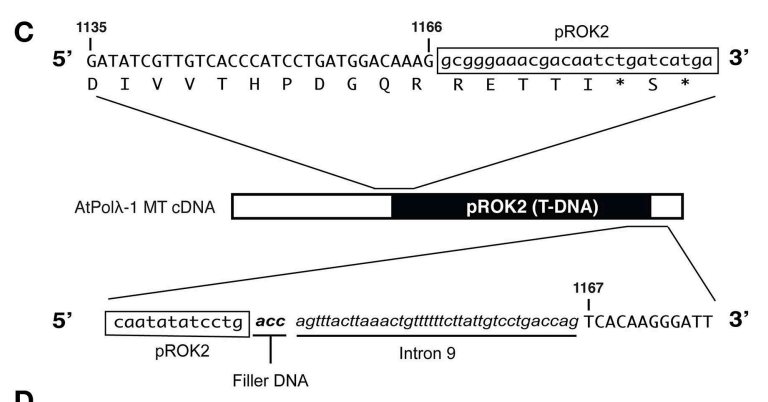

D

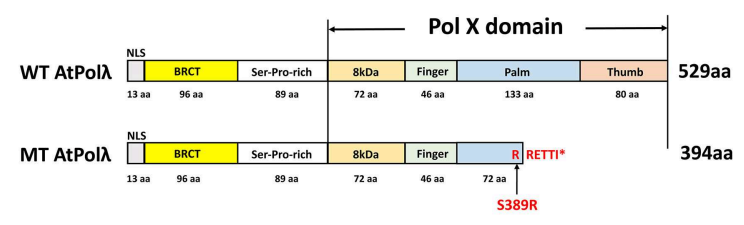

of AtPol $\lambda$ cDNA in atpol $\lambda-1$ mutants. Capitals, AtPol $\lambda$ gene sequence; small letters in the box, pROK2 sequence; small letters/italics/bold, filler DNA; small letters/italics, intron sequence, capitals below a DNA sequence, amino acids; asterisk, stop codon. Each number represents the position of nucleobase in the AtPol $\lambda$ cDNA sequence. (D) Structure of AtPol $\lambda$ proteins in wild type vs atpol $\lambda-1$ mutants. BRCT, BRCA1-C terminal domain; Pol X, DNA polymerase domain conserved among Pol X-family members.

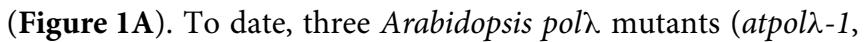
atpol $\lambda$-2, and atpol $\lambda-3$ ) have been isolated from the SALK T-DNA insertion line (Roy et al., 2011). Because both the SALK_075391C mutant and the atpol $\lambda-1$ mutant reported by Roy have the same allele, we designate this mutant as atpol $\lambda-1$. The effect of TDNA insertion on transcription of AtPol $\lambda$ in atpol $\lambda-1$ mutants was investigated by RT-PCR. No amplification was obtained by RT-PCR with the pol $\lambda-1 \mathrm{BF} /$ pol $\lambda-1 \mathrm{BR}$ primer combination, while other two primer combinations aiming to amplify either upstream or downstream region of the T-DNA insertion site produced RT-PCR products, suggesting that the homozygous mutant does not express a wild-type transcript (Figure 1B), as previously observed (Roy et al., 2011). Sequencing of the AtPol $\lambda$ transcript in the mutant revealed that this transcript contains partial sequences of T-DNA and intron 9 and that the joint between the T-DNA's right border and intron 9 includes filler DNA (Figure 1C). Thus, this insertion event generates a new stop codon inside of the pol $\mathrm{X}$ domain of the AtPol $\lambda$ protein, which, if translated, would result in the C-terminal truncation (Figure 1D). This predicted mutant AtPol $\lambda$ protein would contain a BRCT domain in the $\mathrm{N}$-terminal region. The pol $\mathrm{X}$ domain plays a critical role in DNA synthesis, while the BRCT domain interacts with other DNA repair proteins (Leung and Glover, 2011). Thus, we regarded atpol $\lambda-1$ as a loss-of-function mutant lacking in a DNA synthesis capability but still retaining an ability to interact with other proteins. The atpol $\lambda-1$ mutants are fertile and develop normally, and did not show any obvious phenotypic differences compared to with wild-type Col plants (data not shown).

\section{Sensitivity of the atpol $\lambda-1$ mutant to Various DNA Damages}

Previous studies have reported that mammalian Pol $\lambda$ is involved in NHEJ and short-patch BER (Fan and Wu, 2004; Lee et al., 2004; Braithwaite et al., 2005a,b, 2010; Garcia-Diaz et al., 2005; Nick McElhinny et al., 2005). However, mice Pol $\lambda$ deficient cells showed hypersensitivity to oxidative DNA damages but not to ionizing radiation (IR) (Kobayashi et al., 2002; Braithwaite et al., 2005b). This paradox might arise from the fact that mammals have four pol X family polymerases whose functions are partly overlapped. Higher plants are ideal organisms to study functions of Pol $\lambda$ gene because $\mathrm{Pol} \lambda$ is the only member of the pol X-family in higher plants. In order to investigate its role in plant DNA repair, we first examined sensitivity of atpol $\lambda-1$ mutants to various types of DNA damage by comparing root growth with or without DNA damaging treatments. The atpol $\lambda-1$ mutants showed wild-type levels of sensitivity to methylmethane sulfonate (DNA alkylation), mitomycin C (cross-links), and methyl viologen (oxidative damage) when compared to wild-type plants (Figures 2A-C). UV radiation induces both cyclobutane pyrimidine dimers (CPDs) and 6-4 photoproducts (6-4 PPs) in DNA. These UV-B induced damages are repaired via blue-lightdependent photorepair catalyzed by photolyases and through light-independent nucleotide excision repair (NER). Growth of the light-treated atpol $\lambda-1$ mutants after UV-B irradiation was similar to wild type, while the mutant grown under orange light showed a slightly increased, but not statistically significant, resistance at the dose of $6 \mathrm{kJm}^{-2}$ (Figures 2D,E). The atpol $\lambda-1$ mutants exhibited a mild but statistically significant sensitivity to 

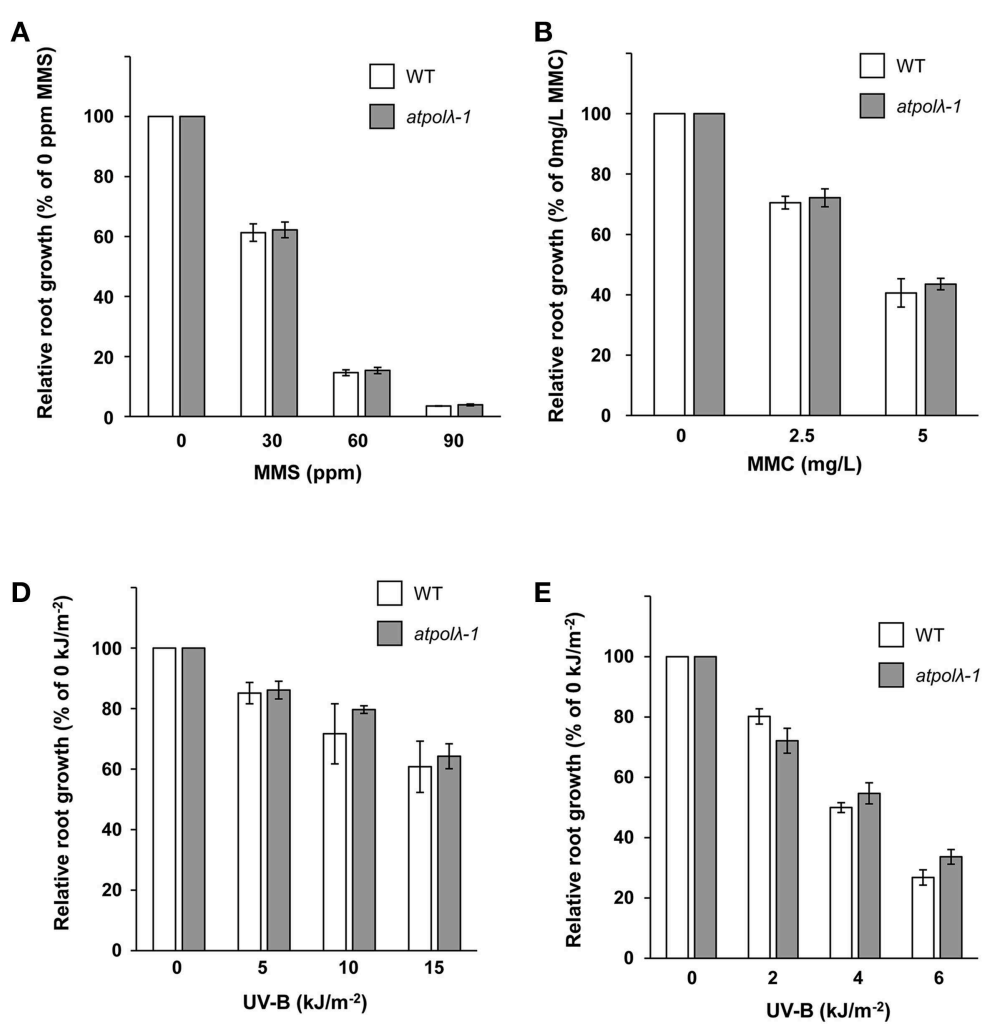

FIGURE 2 | Sensitivity of the atpo/ $\lambda-1$ mutant to various DNA damages. Sterilized wild-type and atpol $\lambda-1$ seeds were sown on solid MS agar containing methylmethano sulfate (A) mitomycin $\mathbf{C}(\mathbf{B})$, or methyl viologen (C), and root length was measured after 7 days. The 3 day-old wild-type and atpol $\lambda-1$ seedlings grown on MS plates were exposed to UV-B, and then grown for two more days under normal light (D) or orange light (E). Sterilized wild-type and atpol $\lambda-1$ seeds were $\gamma$-irradiated and sown on MS-agar plates. Root length was measured after 7 days (F).
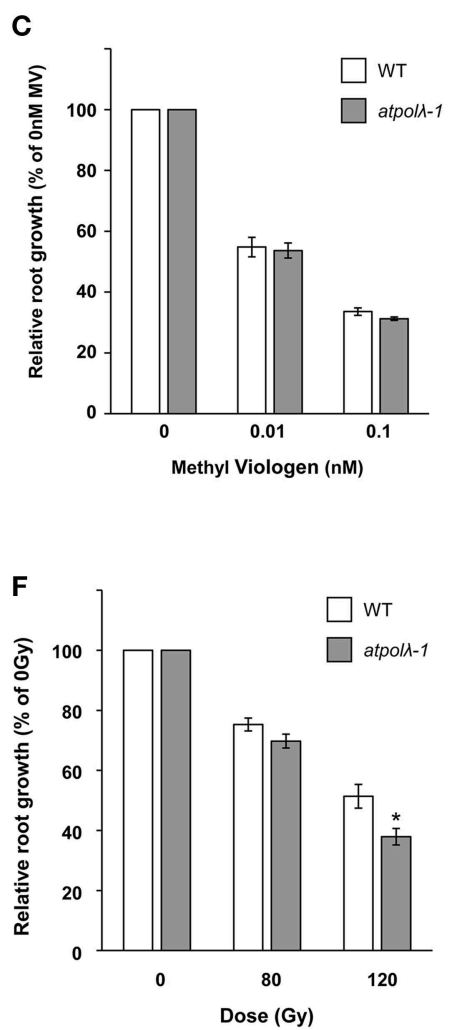

Error bars represent the standard error of the mean of three independent experiments with 24-32 seedlings (average $n=30$ ) for 2A, with 23-36 seedlings (average $n=28$ ) for 2B, with 15-32 seedlings (average $n=25$ ) for 2C, with 13-23 seedlings (average $n=20$ ) for 2D, with 12-19 seedlings (average $n=15$ ) for 2E, and with 18-48 seedlings (average $n=28$ ) for $2 \mathrm{~F}$ per line, per concentration, per replicate plates. The difference in relative root growth between wild type and atpol $\lambda-1$ mutants was significant at 120 Gy in Panel (F) ${ }^{*} p<0.05, t$-test).
IR. Irradiation of $\gamma$-ray at a dose of $120 \mathrm{~Gy}$ inhibited root growth of atpol $\lambda$ - 1 mutants more effectively that of wild-type plants $(P<$ 0.05 , Figure 2F). Next, we tested the effects of $\gamma$-irradiation on formation of true leaves. The size of $\gamma$-irradiated seedlings was

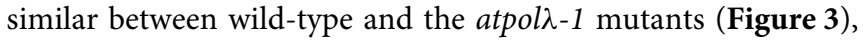
however the number of true leaves was decreased in the 100 Gy-irradiated atpol $\lambda-1$ mutants $(P<0.05$, Table 1). Gamma irradiation induces both DNA double strand breaks (DSBs) and oxidative damage. Given that we had not observed sensitivity to methyl viologen, this result suggests that AtPol $\lambda$ may be involved in DSB repair.

\section{Genetic Analysis of AtPol $\lambda$ Function in DSB Repair}

DSBs are repaired through both NHEJ and HR (homologous recombination) pathways. $\mathrm{Ku}$ heterodimer (Ku70 and Ku80) and Lig4 play a critical role in NHEJ in all eukaryotes, their homologs have been identified in Arabidopsis (Bundock et al., 2002; Riha et al., 2002; Tamura et al., 2002; Friesner and Britt, 2003), and Arabidopsis mutants defective in these genes are hypersensitive to IR. Our observations that the atpol $\lambda-1$ mutants showed sensitivity to IR imply that Pol $\lambda$ may be involved in the repair of IR-induced breaks in Arabidopsis. To elucidate the relation between AtPol $\lambda$ and these NHEJ core genes in DSB repair, we made double knockout mutants by crossing atpol $\lambda$ 1 with either atku70-3, a newly isolated T-DNA mutant from the SALK T-DNA insertion collection in the Col background (Figure S1), or the atlig4-2 mutant (Friesner and Britt, 2003). IR did not influence true leaf formation of wild-type plants, while the number of true leaves was decreased in the $80 \mathrm{~Gy}$ - and 100 Gy-irradiated atpol $\lambda-1$ mutants (Table 1). Inhibition of true leaf formation clearly appeared in four mutants except the atpol $\lambda$ 1 mutants irradiated as seeds at $40 \mathrm{~Gy}$ radiation (Table 1). At this dose, the atlig4-2 mutant was able to produce at least one true leaf on average while irradiated atpol $\lambda$-1/atlig4-2, atku70-3, and atku70-3/atpol $\lambda-1$ mutants produced less than one true leaf. Seven days after 60 Gy or higher dose $\gamma$-irradiation, formation of true leaves was severely inhibited in atlig4-2 and atku70-3, as previously observed. The double atpoli-1/atlig4-2 and atku703/atpol $\lambda-1$ mutants were not significantly more sensitive to IR than the atku70-3 and atlig4-2 mutants, although they tended to show slightly higher sensitivity than each single mutant (Table 1). 


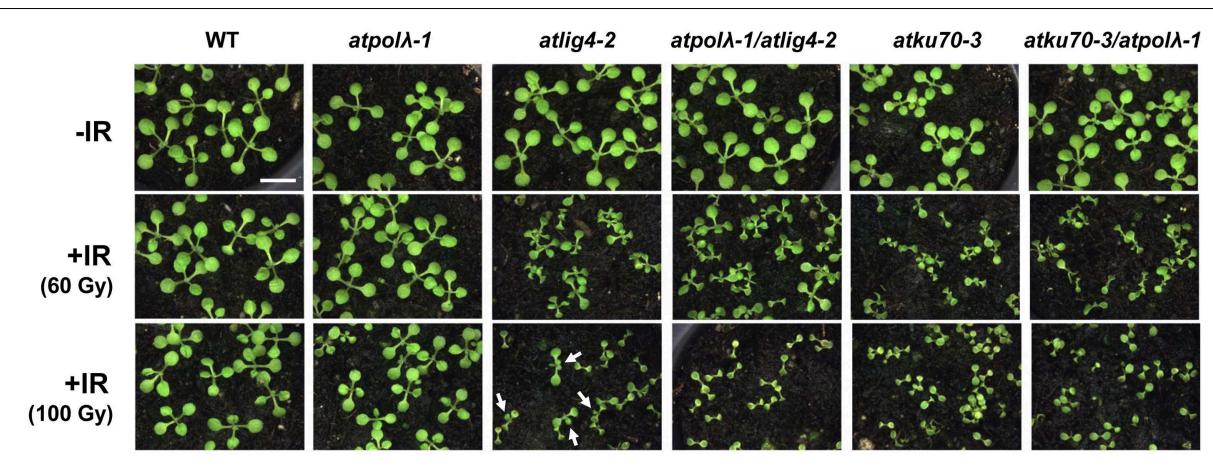

FIGURE 3 | Effects of $\gamma$-irradiation on true leave formation in wild-type and mutant plants. Wild-type and mutant seeds were exposed to gamma-radiation at 0 (mock-irradiation) or $100 \mathrm{~Gy}$, and sown on soil.
These images were captured 10 days after $\gamma$-irradiation. Bar $=1 \mathrm{~mm}$. All pictures were taken at the same magnification. Arrows show true leaves with abnormal shapes produced after $\gamma$-irradiation.

TABLE 1 | The number of true leaves among DSB repair-deficient mutants 7 days after irradiation.

\begin{tabular}{|c|c|c|c|c|c|}
\hline \multirow[t]{3}{*}{ Genotype } & \multicolumn{5}{|c|}{ The number of true leaves 7 days after irradiation (Average \pm SD) } \\
\hline & \multicolumn{5}{|c|}{ Dose (Gy) } \\
\hline & 0 & 40 & 60 & 80 & 100 \\
\hline WT Col & $2.00 \pm 0.00(55)$ & $1.98 \pm 0.03(48)$ & $2.00 \pm 0.00(46)$ & $2.00 \pm 0.00(54)$ & $1.97 \pm 0.04(43)$ \\
\hline atpol $\lambda-1$ & $2.00 \pm 0.00(47)$ & $1.96 \pm 0.06(55)$ & $1.98 \pm 0.02(60)$ & $1.79 \pm 0.05(65)$ & $1.46 \pm 0.08(53)^{\star}$ \\
\hline atlig4-2 & $2.00 \pm 0.00(40)$ & $1.31 \pm 0.14(66)$ & $0.29 \pm 0.06(58)^{\star}$ & $0.05 \pm 0.07(70)^{*}$ & $0.02 \pm 0.03(70)^{*}$ \\
\hline atpol $\lambda-1 / a t l i g 4-2$ & $2.00 \pm 0.00(42)$ & $0.83 \pm 0.08(61)^{\star}$ & $0.23 \pm 0.32(73)$ & $0.00 \pm 0.00(65)^{\star \star}$ & $0.08 \pm 0.11(54)^{\star}$ \\
\hline atku70-3 & $1.92 \pm 0.03(49)$ & $0.75 \pm 0.28(55)$ & $0.11 \pm 0.15(47)^{\star}$ & $0.00 \pm 0.00(57)^{\star \star}$ & $0.00 \pm 0.00(67)^{\star}$ \\
\hline atku70-3/atpoli-1 & $2.00 \pm 0.00(55)$ & $0.57 \pm 0.17(70)^{\star}$ & $0.03 \pm 0.01(63)^{\star \star}$ & $0.03 \pm 0.04(62)^{\star \star}$ & $0.00 \pm 0.00(58)^{\star}$ \\
\hline
\end{tabular}

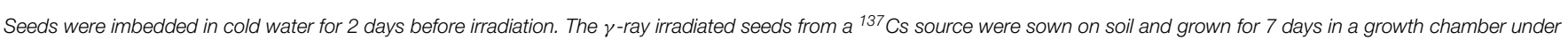

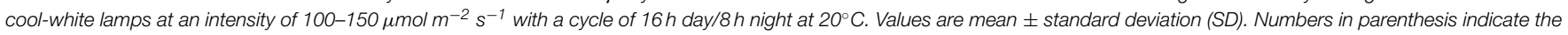
total number of plants scored across all two replicates. * Significant at $P<0.05$; ${ }^{* *}$ significant at $P<0.01$.

Phenotypic difference in true leaf formation among mutants appeared 10 days after $100 \mathrm{~Gy}$ dose irradiation. The wild-type and atpol $\lambda$-1mutants produced normal true leaves and some atlig4-2 mutants were able to produce one or two true leaves with abnormal shapes. However, other three mutants had only cotyledons (Figure 3).

Sensitivity of these mutants to DSBs was also analyzed by investigating the effects of bleomycin (BLM), a radiomimetic reagent that generates DSBs, on root growth (Figures 4A-D). Roots of mutants exposed to BLM exhibited morphological changes such as short root length, swollen root tips, and disorganized layers (Figures 4A,B). Root length of treated plants was similar to those of untreated control plants at $0.35 \mu \mathrm{g} \mathrm{mL}{ }^{-1}$ of BLM. Inhibition of root growth became obvious at $0.7 \mu \mathrm{g}$ $\mathrm{mL}^{-1}$ BLM. The atpol $\lambda-1$ mutants were more sensitive than wildtype plants, but exhibited mild sensitivity when compared to other four mutants. Sensitivity of the atpol $\lambda-1 /$ atlig4-2 double mutants was higher than each atpol $\lambda-1$ and atlig4-2 single mutant $(P<0.05)$. On the other hand, no significant difference

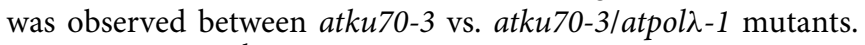
The $1.0 \mu \mathrm{g} \mathrm{mL}^{-1}$ BLM-treated wild type and mutant roots showed a similar inhibition tendency as seen in the $0.7 \mu \mathrm{g} \mathrm{mL}^{-1}$ BLM-treated plants although root length became shorter than that of $0.7 \mu \mathrm{g} \mathrm{mL}^{-1}$ BLM treated-plants (Figure 4C). Next, we examined the timing when swollen root tips appeared after BLM treatment. At $0.1 \mu \mathrm{g} \mathrm{mL}^{-1}$ of BLM, swelling of root tips occurred 2 days after transplant in atlig4-2, atpol $\lambda-1 /$ atlig4-2, atku70-3, atku70-3/atpol $\lambda-1$ mutants although the ratio of abnormal root tip shape differed among four mutants. The atku70-3 mutants were more sensitive than atlig4-2 mutants despite the fact that both genes play critical roles in the canonical NHEJ pathway. Both the atpol $\lambda-1$ mutants and wild type root tips shape appeared to be normal until 3 days after transplant, but became abnormal in the atpol $\lambda-1$ mutants 4 days and in the wild-type plants 7 days after transplant, respectively (Figure 4D). A similar sensitivity pattern among wild-type and mutants was observed even at $0.25 \mu \mathrm{g} \mathrm{mL}^{-1} \mathrm{BLM}$ although the ratio of abnormal root tip in wild-type and the atpol $\lambda-1$ mutants was higher (Table S2).

Taken together, the IR- and BLM-sensitivity indicate that AtPol $\lambda$ has a function in DSB repair in plants. Ku complex and DNA ligase 4 have already been implicated in the canonical NHEJ pathway. It is entirely possible that AtPol $\lambda$ also participates in this $\mathrm{Ku} / \mathrm{Lig} 4$ pathway of NHEJ, but if so, it is not essential for every repair event catalyzed by these enzymes, as the atpol $\lambda-1$ mutant clearly does not share the hypersensitivity of atku70-3 and atlig4-2 to higher doses of BLM and IR. 


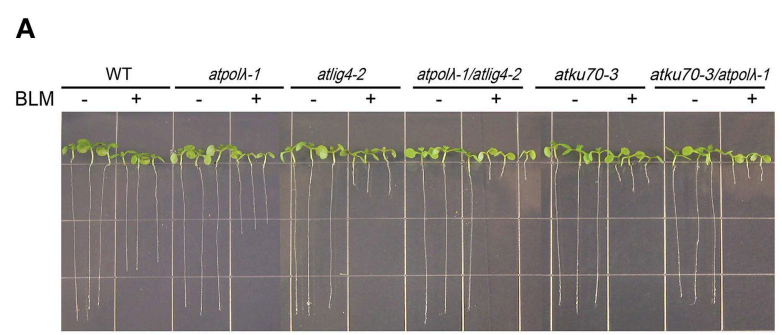

B

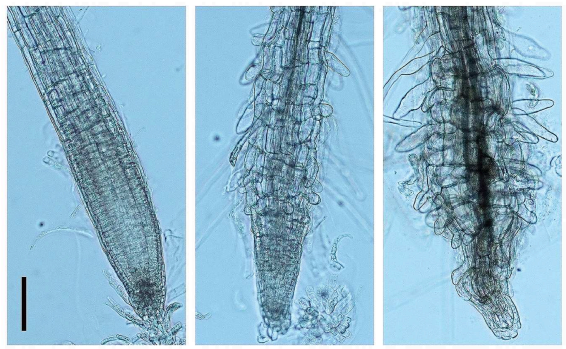

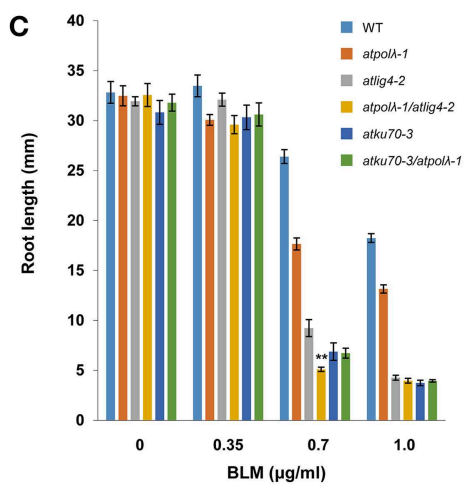

D

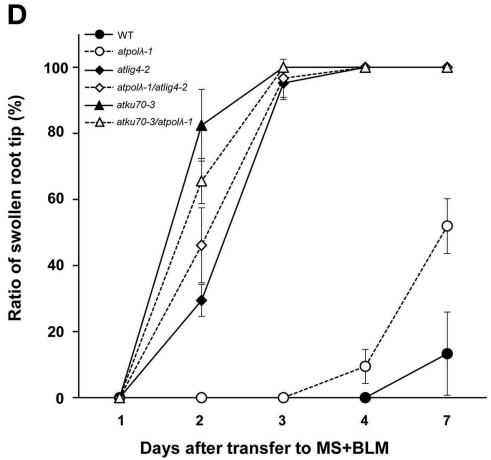

FIGURE 4 | Effects of bleomycin-induced DSBs on root growth. (A) Root length of 1 week-old wild-type and mutant seedlings grown on MS agar containing $0.7 \mu \mathrm{g} \mathrm{mL}^{-1}$ bleomycin (BLM). (B) Morphology of BLM-treated mutant primary root tips. The 3 day-old seedlings were transferred to MS agar plates supplemented without (left panel, mock treatment) or with $0.1 \mu \mathrm{g}$ $\mathrm{ml} \mathrm{mL}{ }^{-1}$ bleomycin (center and right panels). Images were captured 1 day after transfer. Abnormal root tips displayed disorganized root tip structure; randomly swelling cells and emerging of rounded root hairs above the meristem. Bar $=100 \mu \mathrm{m}$. (C) Root length of 1 week-old wild-type and mutant seedlings grown on MS plates containing $0,0.35,0.7$, and $1.0 \mu \mathrm{g}$ $\mathrm{mL}^{-1}$ BLM. Error bar represents the standard error of the mean of three independent experiments with 17-36 seedlings (average $n=29$ ) per line, per concentration, per replicate plates. ${ }^{*}$ Significantly different from the value of the atpol $\lambda-1$ and atlig4-2 mutants ( $\left.{ }^{\star *} P<0.01\right)$. (D) Ratio of abnormal root tips after transplant to MS agar plates containing $0.1 \mu \mathrm{g} \mathrm{ml} \mathrm{mL}{ }^{-1}$ BLM. Error bar represents the standard error of the mean of three independent experiments with 20-23 seedlings (average $n=21$ ) per line, per concentration, per replicate plates.

\section{DNA Damage Response in Mutants}

Previous studies demonstrate that DSBs trigger two robust responses in plants: programmed cell death $(\mathrm{PCD})$ and the ATM/ATR/SOG1-dependent expression of an enormous number of genes (Culligan et al., 2004, 2006; Fulcher and Sablowski, 2009; Yoshiyama et al., 2009; Furukawa et al., 2010). This PCD requires ATM or ATR, and the SOG1 transcription factor and is largely restricted to a specific subset of the cells of the root tip meristem- the precursors of the stele. It is possible that PCD occurs with higher frequency in $\gamma$-irradiated mutant root tips that are deficient in DNA repair. To test this hypothesis, we examined post-irradiation (20 Gy and 80 Gy) PCD events in 5 day-old seedlings of mutant and wild-type plants (Figure 5 and Figure S2). In 20 Gy-irradiated wild-type plants, PCD first occurred sometime between 8 and $24 \mathrm{~h}$ after radiation and the frequency of dead cells was decreasing by $72 \mathrm{~h}$ after radiation (Figure S2). The 20 Gy-irradiated atpold-1 mutants showed a similar cell death pattern to wild-type plants, with perhaps a slight enhancement in the frequency and persistence of dead cells. In contrast, in the other four mutants dead cells were observed by $8 \mathrm{~h}$ after $20 \mathrm{~Gy}$ radiation, the PI-staining was more persistent.
Moreover, initiation of swelling of root tips was observed in the atku70-3 mutants at $72 \mathrm{~h}$ after radiation (Figure S2). Gammairradiation at $80 \mathrm{~Gy}$ induced more PCD events in both wild-type and mutants at $8 \mathrm{~h}$ after radiation (Figure 5). Enlargement of

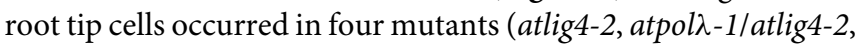

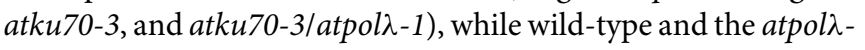
1 root tips displayed slightly swollen but still kept normal root tip shape. These results suggest that AtPol $\lambda$ is involved in resistance to IR-induced meristematic death, but is not as critical to this process as AtKu70 or AtLig4.

Next, we performed quantitative RT-PCR (qRT-PCR) to investigate whether lack of NHEJ influences transcriptional responses to IR (Figures 6A-E). Expression of three cell cycle marker genes and two cell cycle checkpoint genes was measured up to $24 \mathrm{~h}$ after $30 \mu \mathrm{g} \mathrm{mL} \mathrm{m}^{-1}$ BLM treatment. AtCDKB2;1 (Figure 6A, G2 phase marker), AtKNOLLE (Figure 6B, M phase marker), and AtHistone4 (Figure 6C, $\mathrm{S}$ phase marker) were selected as each phase-specific marker gene. Our qRT-PCR analysis showed that expressions of all marker genes were significantly downregulated at $1.5 \mathrm{~h}$ after BLM treatment and had not recovered by $24 \mathrm{~h}$ after treatment $(P<0.05$ or $P<$ 


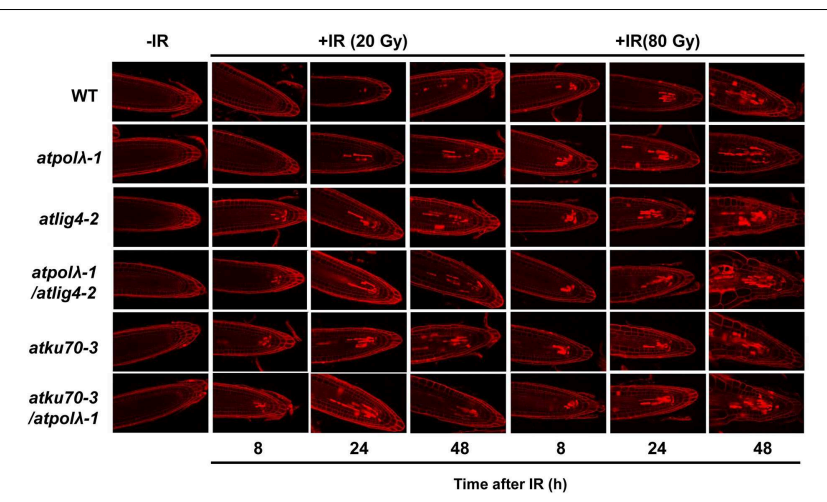

FIGURE 5 | Programmed cell death in wild-type and mutants after IR. The 5 day-old seedlings in each mutant background were exposed to 20 Gy or 80 Gy. Seedling before irradiation were used as control. The $\gamma$-irradiated seedlings were collected at 8,24 , and $48 \mathrm{~h}$ after irradiation and dead cells in root tips were visualized by PI-staining. Bar $=50 \mu \mathrm{m}$.

0.01). We used $A t C Y C B 1 ; 1$ and $A t W e e 1$ as a marker of cell cycle checkpoint genes (Figures 6D,E). AtCYCB1;1 is a plant-specific $B$-type cyclin playing an unique role in DDR pathway, and DSBinducible accumulation of AtCYCB1;1 transcripts reflects $\mathrm{G} 2 / \mathrm{M}$ cell cycle arrest (Culligan et al., 2006). AtWee1 is a protein kinase controlling the progression of plant cell cycle in an ATM/ATRdependent manner; lack of AtWee1 causes extension of S-phase as well as more PCD events in response to replication stresses (Sorrell et al., 2002; De Schutter et al., 2007; Cools et al., 2011). Rapid upregulation of $A t C Y C B 1 ; 1$ occurred in all genotypes at $1.5 \mathrm{~h}$ after BLM treatment although the degree of expression level varied among mutants. The induction of AtCYCB1;1 expression continued at $8 \mathrm{~h}$ after treatment, and DSB-inducible upregulation of AtCYCB1; 1 observed at 1.5 and $8 \mathrm{~h}$ after treatment in wild-type and all mutants was significant $(P<0.05$ or $P<0.01)$. At $24 \mathrm{~h}$ after treatment the expression of AtCYCB1;1 in wild-type and atpol $\lambda-1$ mutants was recovered to the untreated level, whereas it still remained significantly high level in other five mutants $(P<0.05$ in atku70-3 and atku70-3/atpol -1 mutants and $P<$

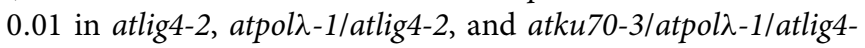
2 mutants). As shown in Figure 6E, an induced expression of

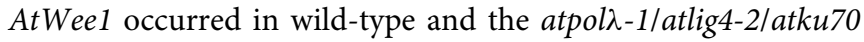
triple mutant at $1.5 \mathrm{~h}$ after treatment $(P<0.01)$. At later time point AtWee1 expression gradually decreased. The AtWee1 expression in wild-type recovered to the untreated level, but high expression of AtWee1 continued in the triple mutant at $8 \mathrm{~h}$ after treatment $(P<0.05)$. Except the triple mutant, the AtWee1 expression was significantly decreased in BLM treated plants at $24 \mathrm{~h}$ after treatment $(P<0.05$ or $P<0.01)$. Taken together, these expression data suggest that DSB-inducible G2/M cell cycle arrest equally occurs in both wild-type and six mutants and that DSBs may prolong the duration of S-phase of the atku70-3/atpol $\lambda$-1/atlig4-2 triple mutant.

It is possible that lack of $A t P o l \lambda$ and other NHEJ-involved genes may induce expression of substitute DNA repair genes to compensate for lost functions. To test this hypothesis, expressions of Arabidopsis BRCA1 (as a positive control for induction), Ku80, and three DNA ligases (Lig1, Lig4, and Lig6) were measured by qRT-PCR immediately after BLM treatment $(t=0)$ and after 20 and 60 min of repair recovery (Figures 7A-C). BRCA1, breast cancer susceptibility gene 1 , is a signal transducer largely linked to the ATM pathway required for the efficient repair of DSBs by homologous recombination in somatic cells of $A$. thaliana with strongly induced transcription by IR (Lafarge and Montane, 2003). DSBs generated by BLM treatment strongly upregulated $A t B R C A 1$ expression in wild-type and mutants (Figure 7A). AtBRCA1 expression in the atpol $\lambda-1$ mutant was dramatically enhanced from 10 - at $t=0$ to 33 fold after $60 \mathrm{~min}$ of repair, and even higher induction from 10to 40 -fold was observed in the atpol $\lambda$-1/atlig4-2 double mutants. In all other lines, the expression of AtBRCA1 during repair period was only slightly higher than that of wild-type and ranged from 10 - to 20 -fold. In contrast to AtBRCA1, the expression of $A t K u 80$ was not significantly induced after BLM treatment. AtKu80 expression resulted in 2- to 6-fold increase compared to untreated controls during the recovery period (Figure $7 \mathbf{B}$ ). Except the atku70-3/atpold-1/atlig4-2 mutant AtKu80 expression tended to increase as the recovery time went. AtKu80 expression was significantly induced in wild-type and the atku70-3/atpol $\lambda$ 1 mutants at $20 \mathrm{~min}$ after treatment $(P<0.05$ or $P<0.01$, Figure 7B). Figure 7C showed DSB-induced upregulation of three DNA ligase genes in wild-type and mutants. In wild-type, all assayed ligases were slightly induced (2- to 3-fold) compared to untreated control, and they showed a similar expression pattern during repair period. At 20 and $60 \mathrm{~min}$ after BLM treatment AtLig1 and AtLig4 expressions were different from expressions at 0 min after treatment $(P<0.05)$. An induction pattern of ligase genes among all mutant lines differed from wild-type.

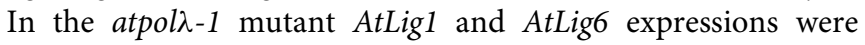
induced during the repair period, but no induction of AtLig4 occurred. The expression of AtLIG1 increased from 2.2-to 5.1fold during the repair period, and AtLig6 expression showed 2.5 -fold increase at $60 \mathrm{~min}$ after treatment. Compared to wildtype, AtLig1 expression was strongly induced in mutants whose genetic background was atlig4-2 (atlig4-2, atpol $\lambda$-1/atlig4-2, and atku70-3/atpoli-1/atlig4-2). The strong induction of AtLig1 expression was also observed in the atpol $\lambda-1 /$ atku70-3 mutants. It reached up to 15 -fold increase at 0 min after treatment and then constantly kept a high level of expression even $60 \mathrm{~min}$ after treatment. Interestingly, the expression of AtLig6 was gradually increased 3- to 10-fold in all AtLig4 mutated lines during recovery period $(P<0.05$ or $P<0.01)$, while AtLig6 expression was not significantly induced in the atku70-3/atpol $\lambda-1$ mutant. In the atku70-3 mutants, only AtLig1 expression was slightly induced after treatment although its expression level was lower than wild-type.

\section{Lack of AtPol $\lambda$ and Other NHEJ-Involved Genes Affects Transformation Efficiency}

It has been reported that DSB repair plays a critical role in integration of transgenes in plants (Friesner and Britt, 2003; Li et al., 2005; Mestiri et al., 2014). In order to uncover functions of these DSB repair genes in this process, we investigated their transformation efficiency using the pFLUAR101 reporter construct. This pFLUAR101 reporter construct contains both the promoter for the seed storage protein napin driving the DsRED gene. Transformed embryos display red fluorescence due 


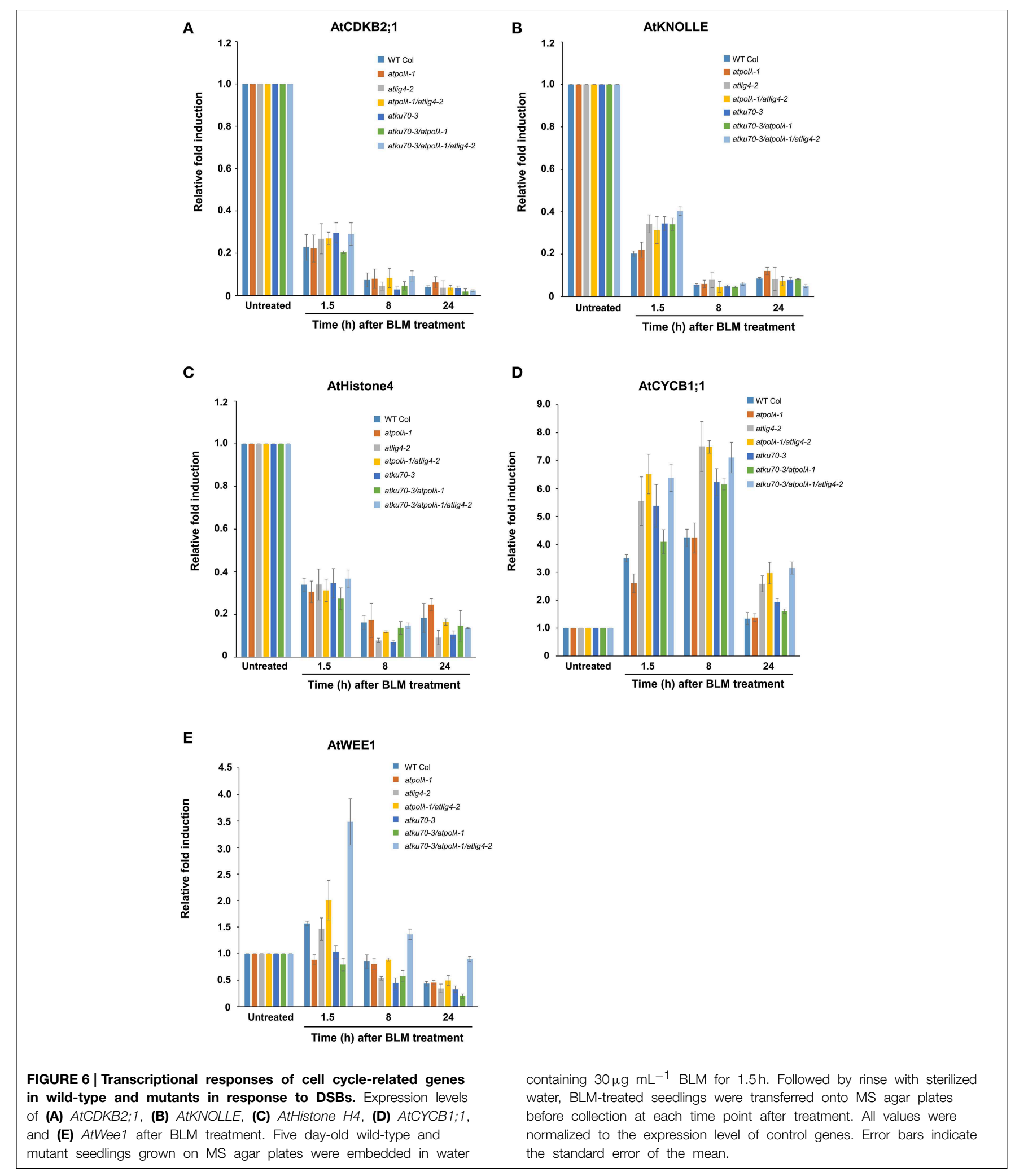

to accumulation of the DsRED protein. This enables us to identify transformed seeds using a fluorescent microscope (Stuitje et al., 2003). The pFLUAR101 construct was transformed into wild-

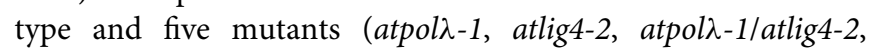

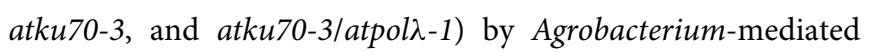
floral dip, and then the transformation efficiency of each plant line was calculated based on the number of $T_{1}$ DsRED seeds (Figure 8 and Table S3). All DSB-deficient mutants tended to 

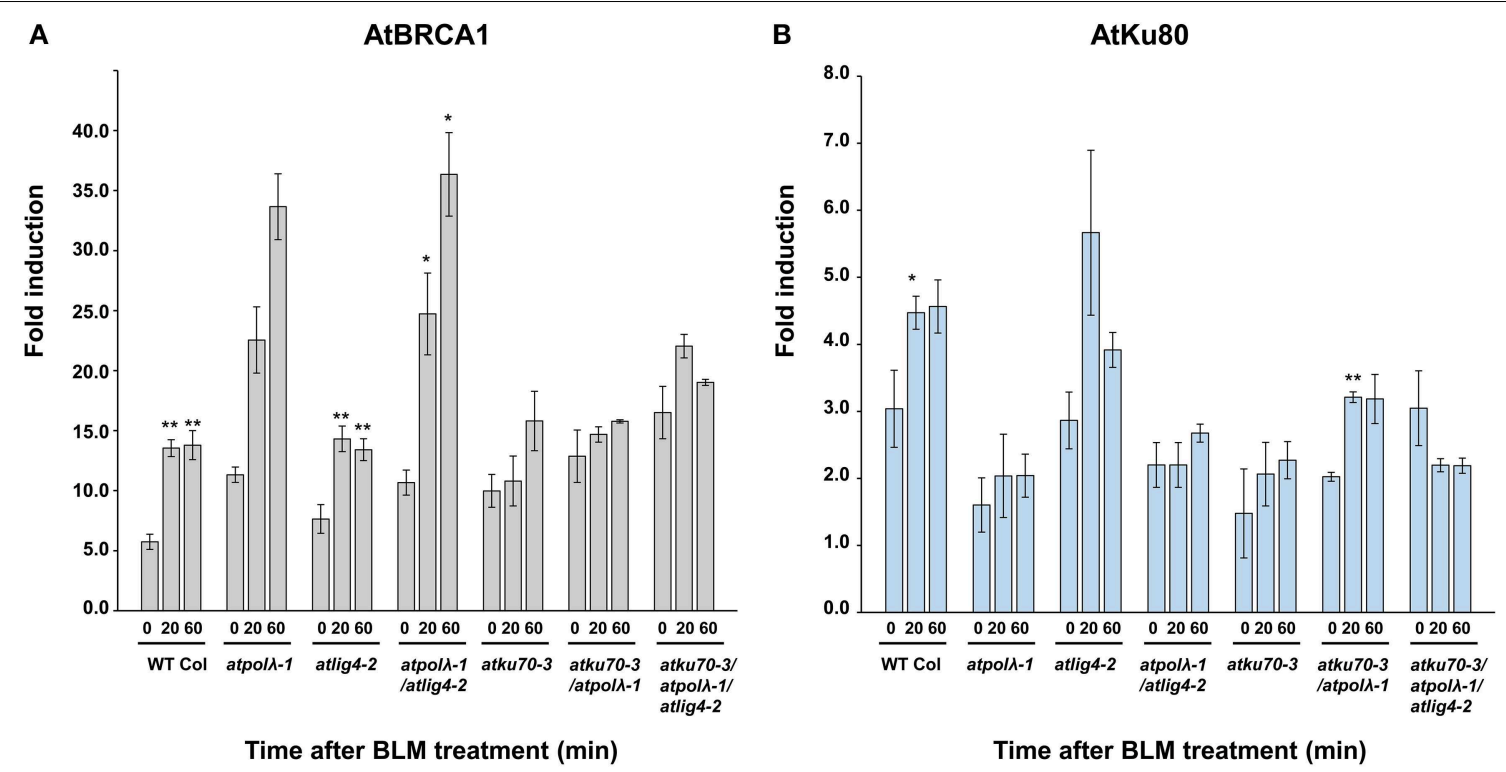

C DNA Ligases

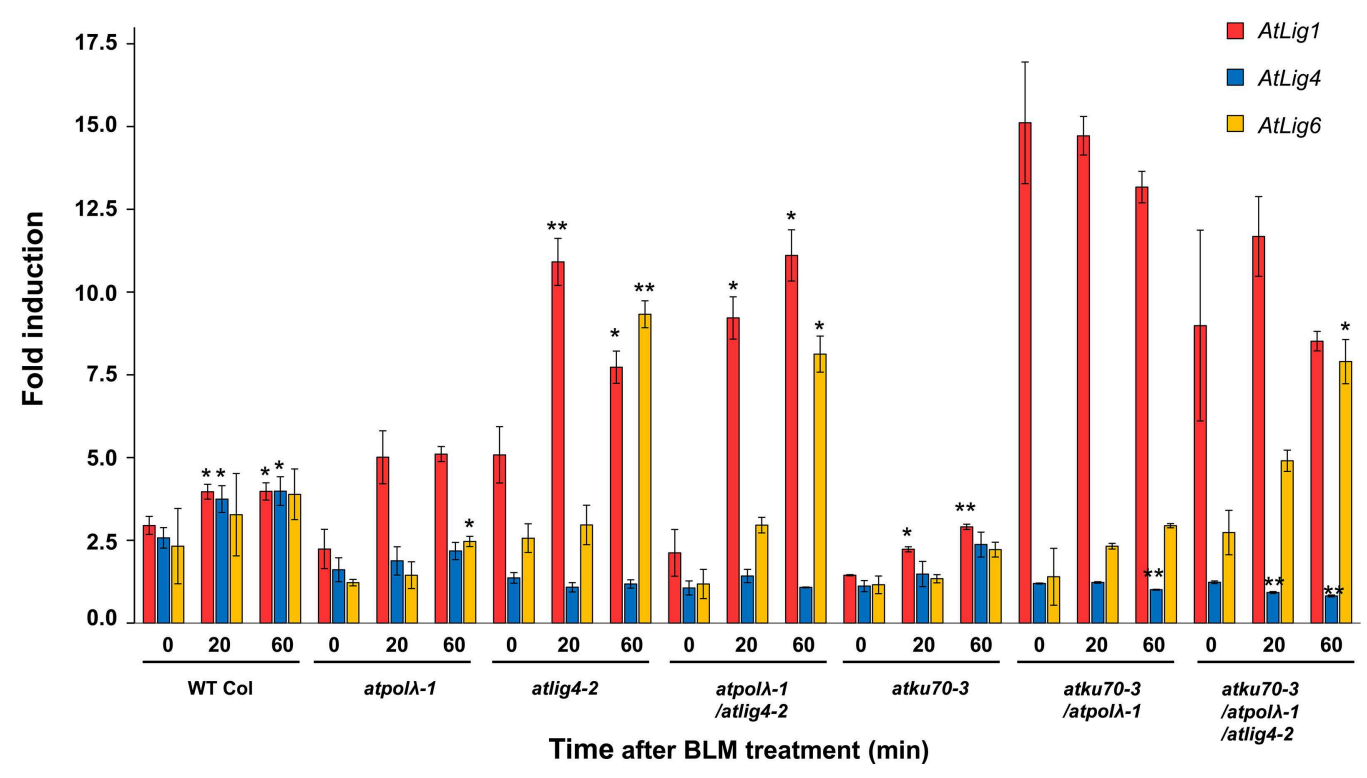

FIGURE 7 | Transcriptional responses of DSB repair genes in wild-type and mutants in response to DSBs. Expression levels of (A) AtBRCA1, (B) AtKu80, and (C) DNA ligases (AtLig1, AtLig4, and AtLig6) after BLM treatment. Five day-old wild-type and mutant seedlings grown on MS agar plates were embedded in water containing $30 \mu \mathrm{g} \mathrm{mL}^{-1}$ BLM for $1 \mathrm{~h}$. Followed by rinse with sterilized water, BLM-treated seedlings were transferred onto MS agar plates before collection at each time point after treatment. All values were normalized to the expression level of control genes, and then relative expressions compared to untreated controls were calculated. Error bars indicate the standard error of the mean. ${ }^{*}$ Significant at $P<0.05$; **significant at $P<0.01$. show a lower transformation efficiency than wild-type plants in each trial despite the fact that it was not statistically significant due to a wide range of transformation efficiencies over three trials

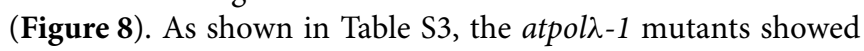
a lower transformation efficiency than wild-type, and tended to exhibit lower efficiency than atlig4-2 and atku70-3 mutants. The reduction of transformation efficiency of the atpol $\lambda-1$ was 1.5 - to 8-fold compared to wild-type, 1.7- to 3.0-fold for atlig4-2, and
1.3- to 3.0-fold for atku70-3, respectively. The atpold-1/atlig42 double mutants showed a lower transformation efficiency than atpol $\lambda-1$ or atlig4-2 single mutant and its transformation efficiency in each trial was the lowest among five mutants (Table S3). In contrast, no significant difference was observed among atku70-3, atpol $\lambda-1$, and atku70-3/atpol $\lambda-1$ mutants (Figure 8). These results suggest that AtPol $\lambda$ may play a more important role in transgene integration than either AtLig4 or AtKu70. 


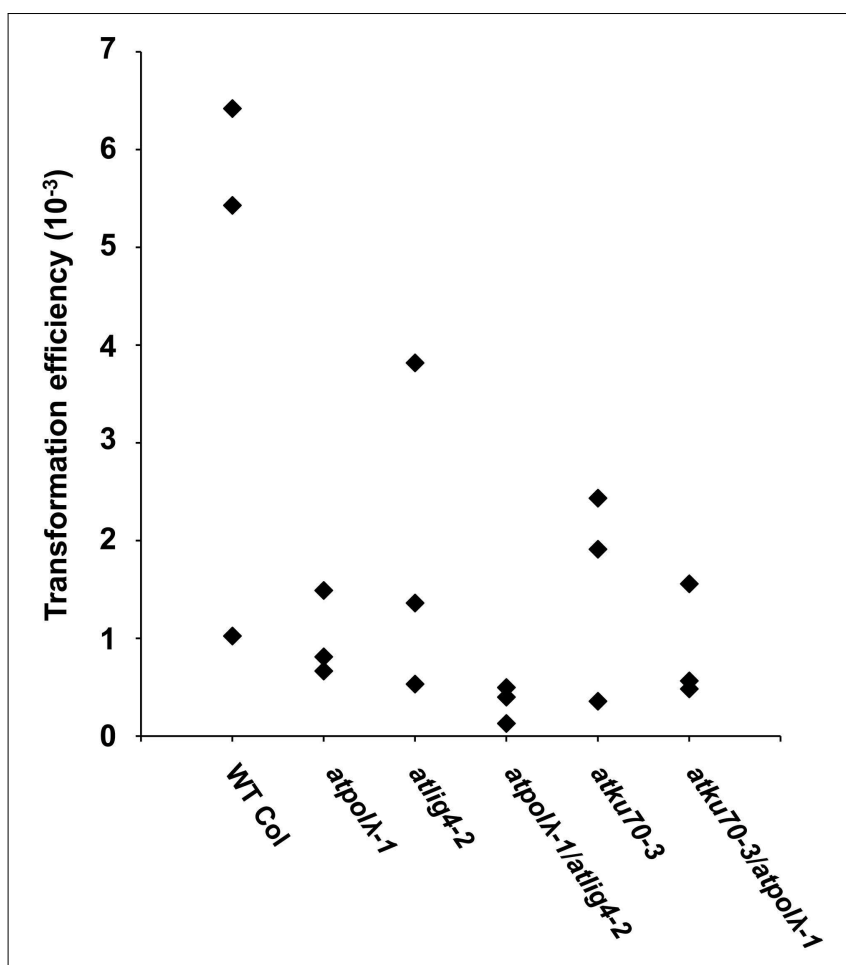

FIGURE 8 | Transformation efficiency in wild-type and DSB-deficient mutants. The pFLAR101 vector was transformed into $T_{0}$ plants through Agrobacterium-mediated floral dipping and $T_{1}$ seeds were harvested as described in Materials and Methods. The $T_{1}$ transformed seeds overexpressing the DsRED protein were selected by fluorescence microscopic observation and transformation efficiency was calculated based on the number of fluorescent seeds. Each rhombus represents transformation efficiency per line per trial. Transformation experiments were repeated three times.

\section{Discussion}

Despite the fact that only Pol $\lambda$ is encoded in plant genomes among Pol-X family members, its biological function is poorly understood. In this paper, we took a reverse genetic approach to study Pol $\lambda$ functions in various plant DNA repair pathways. The expression of Pol $\lambda$ is induced by MMS treatment, MMC treatment, and UV-B radiation, suggesting that plant Pol $\lambda$ may participate in repair of alkylated DNA, DNA crosslink, and UV-damaged DNA (Uchiyama et al., 2004; Roy et al., 2011, 2013). However, the atpol $\lambda-1$ mutant exhibits sensitivity to DSBs caused by IR or bleomycin treatment, but does not display hypersensitivity to other DNA damages such as DNA alkylation (MMS), crosslink (MMC), oxidative damages (MV), and UV damages such as CPDs and 6-4 PPs (UV-B). Analysis of the AtPol $\lambda$ transcript in the atpol $\lambda-1$ mutant reveals that the transcriptional error occurs in this mutant, which results in producing the truncated Pol $\lambda$ protein (Figure 1D). The intact AtPol $\lambda$ protein consists of two major domains; $\mathrm{N}$-terminus and Pol $\beta$-like C-terminus (Roy et al., 2011). The N-terminus, which is comprised of 198 amino acid residues (aa), includes a nuclear localization signal (13 aa), a BRCT domain (96 aa), and a SerPro-rich domain (91 aa). The C-terminus domain is occupied by the Pol X domain (329 aa) consisting of $8 \mathrm{kDa}$ domain as well as fingers, palm and the thumb subdomains. Insertion of T-DNA of the atpol $\lambda-1$ occurs in in intron within the palm subdomain of the Pol X domain. The loss of half of the palm, the entire thumb, and several catalytic residues (the equivalent of the human Pol $\lambda$ amino acids R488 and E529, as described in Cisneros et al. (2008) and aligned in Roy et al., 2013) indicates that this truncated protein lacks any significant DNA polymerase activity. In contrast, the mutant protein still contains the intact $8 \mathrm{kDa}$ and BRCT domains and might possess dRP lyase activity if the mutant protein is stable. In an earlier study (Roy et al., 2013), Roy et al. analyzed three different alleles (including atpol $\lambda-1$ ), and found no sensitivity to MMS. The atpol $\lambda-2$ and atpol $\lambda-3$ mutants carry insertions in the 5' UTR and the last exon, respectively, and thus might conceivably express an functional protein, however, the authors were unable to detect Pol $\lambda$ via Western blot and therefore the level of this protein of wild-type size in these two mutants, must be quite low. Thus, we propose two possibilities to explain the lack of sensitivity of the atpol $\lambda-1$ mutants to MMS treatment; (1) the truncated Pol $\lambda$ protein may play a role in repair of alkylated and oxidative DNA damages via preserved dRP lyase activity (though this would require that atpol $\lambda-2$ and atpol $\lambda-3$ are also expressing a functional protein, though none was detected via Western blot). (2) Plants prefer to use a Pol $\lambda$ independent repair pathway such as long-patch BER to repair AP sites generated by base repair glycosylases (we regard this as the simpler and more likely hypothesis).

In our hands the atpol $\lambda-1$ mutant did not display UV-B sensitivity when irradiated as a seedling and then cultivated under non-photoreactvating light. We used the Arabidopsis XPF (atxpf-2) mutant as a control in our root-bending assay under dark condition because it was hypersensitive to UV-B radiation due to lack of NER (Jiang et al., 1997; Fidantsef et al., 2000). The relative root growth of UV-B irradiated atxpf-2 mutants was decreased to $24 \%$ at a dose of $2 \mathrm{~kJ} \mathrm{~m}^{-2}$ and to $6 \%$ at 4 $\mathrm{kJ} \mathrm{m}^{-2}$ compared to unirradiated control plants (unpublished data), which indicates that our UV-B treatment produces UV damages that sufficiently inhibit root growth of NER-deficient mutants. In contrast to our observation, the atpol $\lambda-1$ mutant showed hypersensitivity when seeds were exposed to UV-B and seedlings germinated from UV-B radiated seeds had slower repair rates for both CPDs and DSBs (Roy et al., 2011). The 5 day-old atpol $\lambda-1$ mutant seedlings were radiated with UV$\mathrm{B}$ for a short period (ex. $18 \mathrm{~s}$ radiation for $1 \mathrm{~kJ} \mathrm{~m}^{-2}$ ) in our experiment, whereas mutant seeds are irradiated for $60 \mathrm{~min}$ at the dose of $5.4 \mathrm{~kJ} \mathrm{~m}^{-2}$ before sowing in Roy's experiment. About sensitivity to MMC, the sensitive phenotype of the atpol $\lambda$ 1 mutants is observed only when mutant plants are grown on MS agar plates supplemented with $10 \mu \mathrm{g} \mathrm{ml}^{-1} \mathrm{MMC}$, and the phenotypic difference between wild-type plants and the atpol $\lambda-1$ mutants is not statistically significant at 3 and $5 \mu \mathrm{g} \mathrm{ml}^{-1} \mathrm{MMC}$ (Roy et al., 2013). Taken these findings together, it is possible that the effect of Pol $\lambda$ on repair of UV-B induced damage or DNA crosslink is too subtle to detect in our growth assay and that bombardment of high-dose UV radiation for a long period or MMC treatment of mutant plants at higher concentration may be necessary to cause hypersensitive phenotype. Besides CPDs and 6-4 PPs, it is also known that UV-B radiation often 
induces reactive oxygen species that cause oxidative damages to DNA. Accumulation of unrepaired single strand breaks is often converted to DSBs if positions of breaks in the genome are very close. Interstrand crosslinks (ICLs) generated by MMC at replication forks stall the process of DNA replication, and then the collapse of ICL-stalled replication forks provokes DSBs. In this paper we have demonstrated by IR and radiomimetic chemical treatment that the atpol $\lambda-1$ mutants display mild sensitivity to DSBs. Therefore, it could be also possible that hypersensitivity of atpol $\lambda-1$ mutants to UV-B and MMC may reflect sensitivity to DSBs as well as direct UV damages (CPDs and 6-4 PPs) or ICLs.

As in animals, DSBs are thought to be mainly repaired by $\mathrm{Ku}$ - and Lig4-dependent NHEJ in plants (West et al., 2000, 2002; Bundock et al., 2002; Riha et al., 2002; Friesner and Britt, 2003; Gallego et al., 2003). Both atku70 and atlig4-2 mutants show hypersensitivity to DSBs generated by gammairradiation or BLM treatment. Unlike these NHEJ-deficient mutants, the sensitivity of the atpol $\lambda-1$ mutants is only observed when mutants are gamma-irradiated at high dose (100 Gy and $120 \mathrm{~Gy}$ ) or treated with a high concentration of BLM $\left(0.7 \mu \mathrm{g} \mathrm{mL}^{-1}\right.$ and $\left.1.0 \mu \mathrm{g} \mathrm{mL}^{-1}\right)$. Moreover, the fraction of root tips with disorganized structure in the atpol $\lambda-1$ mutants is lower than that of atku70 or atlig4-2 mutant. The observation that the atpol $\lambda-1$ mutant exhibits a mild sensitivity to IR suggests that AtPol $\lambda$ participates in DSB repair, just as it participates in DSB repair in mammals. Results using double mutants provide additional hints to consider $\mathrm{Pol} \lambda$ functions in NHEJ. The atpol $\lambda$-1/atlig4-2 double mutant always shows higher sensitivity than each single mutant, while the sensitivity of the atku70/atpol $\lambda-1$ double displays similar sensitivity to the atku70 mutant. In canonical NHEJ, broken ends of DNA strands are first shielded by the Ku70/Ku80 heterodimer and then the Lig4/XRCC4 complex ligates guarded DNA ends. Although AtKu70 and AtLig4 functions in the same NHEJ pathway, we found that the atku70 mutant is more sensitive to DSBs than the atlig4-2 mutant. Taken together, these results suggest that plants may have two pathways for DSB repair, AtLig4-dependent canonical (C-NHEJ) and AtLig4-independent alternative (ANHEJ), pathways downstream of the DNA protection process catalyzed by AtKu70/AtKu80. Our results also suggest that AtPol $\lambda$ is employed in A-NHEJ. Recent studies on mammalian DSB repair have shown that microhomology-mediated end joining (MMEJ) is one of backup NHEJ pathways in which Ku80 and poly(ADP-ribose) polymerases (PARP) play essential roles. In vitro studies show that human DNA polymerase $\lambda$ and Lig1, but not Lig4, are required for sufficient MMEJ reaction (Liang et al., 2008; Crespan et al., 2012). Similar to mammals, a study using RNAi-silenced AtLig1 demonstrates that AtLig1 plays an important role in DSB repair as well as single strand break repair (Waterworth et al., 2009). In addition, our qRT-PCR analysis reveals that DSBs induce expression of AtLig1 and AtLig6 in mutants lacking AtLig4. Given that Ku80 and PARP-dependent MMEJ is conserved in plants (Jia et al., 2013), our data are consistent with a model in which AtPol $\lambda$ functions in some ANHEJ pathway, (possibly MMEJ), in concert with AtLig1 and/or AtLig6.
Recent studies have demonstrated that plants have a robust DNA damage response to DSBs (Culligan et al., 2006; Ricaud et al., 2007; Yoshiyama et al., 2009; Furukawa et al., 2010; Missirian et al., 2014). To investigate the role of AtPol $\lambda$ in DDR, we investigated both the frequency of PCD and the transcriptional response after BLM treatment. Although the number of dead cells is slightly increased in the atpol $\lambda-1$ mutant compared to wild-type, its influence on frequency of PCD is smaller than NHEJ-defective mutants. The DSB-inducible transcriptional response appears to be similar between wild-type and mutants. BLM treatment causes upregulation of AtCYCB1;1 expression, while it downregulates expressions of other cell cycle specific marker genes, AtCDKB2;1, AtKNOLLE, and AtHistone $H 4$. These results suggest that cell cycle is arrested at G2/M in BLM-treated root tip cells although there is no direct evidence. The expression of AtCYCB1;1 remains high level in atlig4-2 mutants at $24 \mathrm{~h}$ after treatment. Given that the high expression of $A t C Y C B 1 ; 1$ is associated with the existence of unrepaired DSBs, this result may reflect that A-NHEJ requires more time to repair DSBs than the AtLig4-dependent pathway does. Moreover, AtWee1 expression is highly induced only in the atku70/atpol $\lambda$ 1/atlig4-2 triple mutant and this high expression continues at $24 \mathrm{~h}$ after treatment. It has been reported that AtWee1 controls many aspects of response to replication blocks (Cools et al., 2011). This result raises the possibility that response to DNA damage of the triple mutant is enhanced because its DSB repair activity via both C-NHEJ and A-NHEJ is completely lost.

It has been reported that NHEJ plays an important role in the integration of a transgene. The efficiency of T-DNA insertion to the plant genome is decreased in atku80 and atlig4 mutants though this effect is not consistently observed (Friesner and Britt, 2003; Li et al., 2005). Given that AtPol $\lambda$ functions in A-NHEJ, the efficiency of T-DNA insertion in the atpol $\lambda-1$ mutant is expected to be decreased as in NHEJ-defective mutants. Decreased TDNA insertion efficiency is observed in the atpol $\lambda-1$ mutant as anticipated. However, its frequency tends to be lower than that of atku70 or atlig4-2 single mutant. The atpol $\lambda-1 /$ atlig4-2 double mutant shows the lowest transformation efficiency among six tested plant lines. These results suggest that T-DNAs may insert via either C-NHEJ or A-NHEJ.

In summary, the results and discussion presented here provide new insights into functions of AtPol $\lambda$ in plant DSB repair. Although AtPol $\lambda$ is suggested to participate in A-NHEJ, much remains unclear about its molecular machinery. Further studies would be required to clarify the role of AtPol $\lambda$ in A-NHEJ.

\section{Acknowledgments}

Experimental design and analysis by $\mathrm{TF}$ and $\mathrm{AB}$, preparation of Arabidopsis T-DNA insertion mutants, and microscopic observations by TF, DNA damaging treatments and irradiations performed by TF and Phillip A. Conklin, qRT-PCR analysis performed by $\mathrm{TF}$ and $\mathrm{KA}$, text and figures prepared by $\mathrm{TF}$, $\mathrm{KA}$, and $\mathrm{AB}$. Work in the Britt lab was funded by DOE Office of Basic Energy Sciences grant no. DE-FG02-05ER15668 and by the National Research Initiate of the USDA Cooperative State Research, Education and Extension Service, grant no. 
2004-35301-14740. Dr. Furukawa was also supported by a Postdoctoral Fellowship for Research Abroad from the Japan Society for the Promotion of Science (JSPS). Work in Angelis Lab was supported by Czech Science Foundation grant no. 13-06595S.

\section{Supplementary Material}

The Supplementary Material for this article can be found online at: http://journal.frontiersin.org/article/10.3389/fpls.2015. 00357/abstract

\section{References}

Amoroso, A., Concia, L., Maggio, C., Raynaud, C., Bergounioux, C., Crespan, E., et al. (2011). Oxidative DNA damage bypass in Arabidopsis thaliana requires DNA polymerase $\lambda$ and proliferating cell nuclear antigen 2. Plant Cell 23, 806-822. doi: 10.1105/tpc.110.081455

Anderson, H. J., Vonarx, E. J., Pastushok, L., Nakagawa, M., Katafuchi, A., Gruz, P., et al. (2008). Arabidopsis thaliana Y-family DNA polymerase eta catalyses translesion synthesis and interacts functionally with PCNA2. Plant J. 55, 895-908. doi: 10.1111/j.1365-313X.2008.03562.x

Braithwaite, E. K., Kedar, P. S., Lan, L., Polosina, Y. Y., Asagoshi, K., Poltoratsky, V. P., et al. (2005b). DNA polymerase lambda protects mouse fibroblasts against oxidative DNA damage and is recruited to sites of DNA damage/repair. J. Biol. Chem. 280, 31641-31647. doi: 10.1074/jbc.C500256200

Braithwaite, E. K., Kedar, P. S., Stumpo, D. J., Bertocci, B., Freedman, J. H., Samson, L. D., et al. (2010). DNA polymerases beta and lambda mediate overlapping and independent roles in base excision repair in mouse embryonic fibroblasts. PLoS ONE 5:e12229. doi: 10.1371/journal.pone.0012229

Braithwaite, E. K., Prasad, R., Shock, D. D., Hou, E. W., Beard, W. A., and Wilson, S. H. (2005a). DNA polymerase lambda mediates a back-up base excision repair activity in extracts of mouse embryonic fibroblasts. J. Biol. Chem. 280, 18469-18475. doi: 10.1074/jbc.M411864200

Bundock, P., van Attikum, H., and Hooykaas, P. (2002). Increased telomere length and hypersensitivity to DNA damaging agents in an Arabidopsis KU70 mutant. Nucleic Acids Res. 30, 3395-3400. doi: 10.1093/nar/gkf445

Capp, J. P., Boudsocq, F., Bertrand, P., Laroche-Clary, A., Pourquier, P., Lopez, B. S., et al. (2006). The DNA polymerase lambda is required for the repair of noncompatible DNA double strand breaks by NHEJ in mammalian cells. Nucleic Acids Res. 34, 2998-3007. doi: 10.1093/nar/gkl380

Cisneros, G. A., Perera, L., Garcia-Diaz, M., Bebenek, K., Kunkel, T. A., and Pedersen, L. G. (2008). Catalytic mechanisms of human DNA polymerase $\lambda$ with $\mathrm{Mg}^{2+}$ and $\mathrm{Mn}^{2+}$ from $a b$ initio quantum mechanical/molecular mechanical studies. DNA Repair (Amst) 7, 1824-1834. doi: 10.1016/j.dnarep.2008.07.007

Cools, T., Iantcheva, A., Weimer, A. K., Boens, S., Takahashi, N., Maes, S., et al. (2011). The Arabidopsis thaliana checkpoint kinase WEE1 protects against premature vascular differentiation during replication stress. Plant Cell 23, 1435-1448. doi: 10.1105/tpc.110.082768

Crespan, E., Czabany, T., Maga, G., and Hubscher, U. (2012). Microhomologymediated DNA strand annealing and elongation by human DNA polymerases $\lambda$ and $\beta$ on normal and repetitive DNA sequences. Nucleic Acids Res. 40, 5577-5590. doi: 10.1093/nar/gks186

Culligan, K., Tissier, A., and Britt, A. (2004). ATR regulates a G2-phase cellcycle checkpoint in Arabidopsis thaliana. Plant Cell 16, 1091-1104. doi: 10.1105/tpc.018903

Culligan, K. M., Robertson, C. E., Foreman, J., Doerner, P., and Britt, A. B. (2006). ATR and ATM play both distinct and additive roles in response to ionizing radiation. Plant J. 48, 947-961. doi: 10.1111/j.1365-313X.2006.02931.x

De Schutter, K., Joubes, J., Cools, T., Verkest, A., Corellou, F., Babiychuk, E., et al. (2007). Arabidopsis WEE1 kinase controls cell cycle arrest in response to activation of the DNA integrity checkpoint. Plant Cell 19, 211-225. doi: $10.1105 /$ tpc. 106.045047
Supplementary Figure 1 | Structure of $K u 70$ gene in the atku70-3 mutant. (A) Schematic structure of the AtKu70 gene and its T-DNA insertion. Arrowheads represent gene-specific primers used for PCR. RB, T-DNA right border; LB, T-DNA left border. (B) Semiquantitative RT-PCR on different regions of the AtKu70 gene. Primer pairs used for RT-PCR were LBb1 + Ku70R (left panel) and Ku7OF + Ku70R (right panel). W, wild type; M, atku70 mutant. (C) Sequence data for T-DNA: DNA junctions in the atku70 mutant. Capitals, AtKu70 gene sequence; Capitals/bold in the box, pROK2 sequence.

Supplementary Figure 2 | PCD and phenotypical differences of WT and mutants after $\boldsymbol{\gamma}$-irradiation. The 5-day-old seedlings in each mutant background were exposed to 20 Gy or mock-irradiated (0 h). The $\gamma$-irradiated seedlings were collected at $72 \mathrm{~h}$ after irradiation and dead cells in root tips were visualized by Pl-staining. Bar $=50 \mu \mathrm{m}$.

Fan, W., and Wu, X. (2004). DNA polymerase lambda can elongate on DNA substrates mimicking non-homologous end joining and interact with XRCC4ligase IV complex. Biochem. Biophys. Res. Commun. 323, 1328-1333. doi: 10.1016/j.bbrc.2004.09.002

Fidantsef, A. L., Mitchell, D. L., and Britt, A. B. (2000). The Arabidopsis UVH1 gene is a homolog of the yeast repair endonuclease RAD1. Plant Physiol. 124, 579-586. doi: 10.1104/pp.124.2.579

Friesner, J., and Britt, A. B. (2003). Ku80- and DNA ligase IV-deficient plants are sensitive to ionizing radiation and defective in T-DNA integration. Plant J. 34, 427-440. doi: 10.1046/j.1365-313X.2003.01738.x

Fulcher, N., and Sablowski, R. (2009). Hypersensitivity to DNA damage in plant stem cell niches. Proc. Natl. Acad. Sci. U.S.A. 106, 20984-20988. doi: 10.1073/pnas.0909218106

Furukawa, T., Curtis, M. J., Tominey, C. M., Duong, Y. H., Wilcox, B. W., Aggoune, D., et al. (2010). A shared DNA-damage-response pathway for induction of stem-cell death by UVB and by gamma irradiation. DNA Repair (Amst). 9, 940-948. doi: 10.1016/j.dnarep.2010.06.006

Furukawa, T., Imamura, T., Kitamoto, H. K., and Shimada, H. (2008). Rice exonuclease-1 homologue, OsEXO1, that interacts with DNA polymerase lambda and RPA subunit proteins, is involved in cell proliferation. Plant Mol. Biol. 66, 519-531. doi: 10.1007/s11103-008-9288-6

Gallego, M. E., Bleuyard, J. Y., Daoudal-Cotterell, S., Jallut, N., and White, C. I. (2003). Ku80 plays a role in non-homologous recombination but is not required for T-DNA integration in Arabidopsis. Plant J. 35, 557-565. doi: 10.1046/j.1365-313X.2003.01827.x

Garcia-Diaz, M., Bebenek, K., Gao, G., Pederson, L. C., London, R. E., and Kunkel, T. A. (2005). Structure-function studies of DNA polymerase lambda. DNA Repair (Amst). 4, 1358-1367. doi: 10.1016/j.dnarep.2005.09.001

Garcia-Diaz, M., Dominguez, O., Lopez-Fernandez, L. A., de Lera, L. T., Saniger, M. L., Ruiz, J. F., et al. (2000). DNA polymerase lambda (Pol lambda), a novel eukaryotic DNA polymerase with a potential role in meiosis. J. Mol. Biol. 301, 851-867. doi: 10.1006/jmbi.2000.4005

Garcia-Ortiz, M. V., Ariza, R. R., Hoffman, P. D., Hays, J. B., and RoldánArjona, T. (2004). Arabidopsis thaliana AtPOLK encodes a DinB-like DNA polymerase that extends mispaired primer termini and is highly expressed in a variety of tissues. Plant J. 39, 84-97. doi: 10.1111/j.1365-313X.2004.0 2112.x

Huefner, N. D., Mizuno, Y., Weil, C. F., Korf, I., and Britt, A. B. (2011). Breadth by depth: expanding our understanding of the repair of transposon-induced DNA double strand breaks via deep-sequencing. DNA Repair (Amst). 10, 1023-1033. doi: 10.1016/j.dnarep.2011.07.011

Inagaki, S., Suzuki, T., Ohto, M. A., Urawa, H., Horiuchi, T., Nakamura, K., et al. (2006). Arabidopsis TEBICHI, with helicase and DNA polymerase domains, is required for regulated cell division and differentiation in meristems. Plant Cell. 18, 879-892. doi: 10.1105/tpc.105.036798

Jia, Q., den Dulk-Ras, A., Shen, H., Hooykaas, P. J., and de Pater, S. (2013). Poly(ADP-ribose) polymerases are involved in microhomology mediated backup non-homologous end joining in Arabidopsis thaliana. Plant Mol. Biol. 82, 339-351. doi: 10.1007/s11103-013-0065-9

Jiang, C. Z., Yen, C. N., Cronin, K., Mitchell, D., and Britt, A. B. (1997). UVand gamma-radiation sensitive mutants of Arabidopsis thaliana. Genetics. 147, 1401-1409. 
Kimura, S., Uchiyama, Y., Kasai, N., Namekawa, S., Saotome, A., Ueda, T., et al. (2002). A novel DNA polymerase homologous to Escherichia coli DNA polymerase I from a higher plant, rice (Oryza sativa L.). Nucleic Acids Res. 30, 1585-1592. doi: 10.1093/nar/30.7.1585

Kobayashi, Y., Watanabe, M., Okada, Y., Sawa, H., Takai, H., Nakanishi, M., et al. (2002). Hydrocephalus, situs inversus, chronic sinusitis, and male infertility in DNA polymerase lambda-deficient mice: possible implication for the pathogenesis of immotile cilia syndrome. Mol. Cell. Biol. 22, 2769-2776. doi: 10.1128/MCB.22.8.2769-2776.2002

Lafarge, S., and Montane, M. H. (2003). Characterization of Arabidopsis thaliana ortholog of the human breast cancer susceptibility gene 1: AtBRCA1, strongly induced by gamma rays. Nucleic Acids Res. 31, 1148-1155. doi: $10.1093 / \mathrm{nar} / \mathrm{gkg} 202$

Lee, J. W., Blanco, L., Zhou, T., Garcia-Diaz, M., Bebenek, K., Kunkel, T. A., et al. (2004). Implication of DNA polymerase lambda in alignment-based gap filling for nonhomologous DNA end joining in human nuclear extracts. J. Biol. Chem. 279, 805-811. doi: 10.1074/jbc.M307913200

Leung, C. C., and Glover, J. N. (2011). BRCT domains: easy as one, two, three. Cell Cycle 10, 2461-2470. doi: 10.4161/cc.10.15.16312

Li, J., Vaidya, M., White, C., Vainstein, A., Citovsky, V., and Tzfira, T. (2005). Involvement of KU80 in T-DNA integration in plant cells. Proc. Natl. Acad. Sci. U.S.A. 102, 19231-19236. doi: 10.1073/pnas.0506437103

Liang, L., Deng, L., Nguyen, S. C., Zhao, X., Maulion, C. D., Shao, C., et al. (2008). Human DNA ligases I and III, but not ligase IV, are required for microhomology-mediated end joining of DNA double-strand breaks. Nucleic Acids Res. 36, 3297-3310. doi: 10.1093/nar/gkn184

Mestiri, I., Norre, F., Gallego, M. E., and White, C. I. (2014). Multiple hostcell recombination pathways act in Agrobacterium-mediated transformation of plant cells. Plant J. 77, 511-520. doi: 10.1111/tpj.12398

Missirian, V., Conklin, P. A., Culligan, K. M., Huefner, N. D., and Britt, A. B. (2014). High atomic weight, high-energy radiation (HZE) induces transcriptional responses shared with conventional stresses in addition to a core "DSB" response specific to clastogenic treatments. Front. Plant Sci. 5:364. doi: 10.3389/fpls.2014.00364

Mori, Y., Kimura, S., Saotome, A., Kasai, N., Sakaguchi, N., Uchiyama, Y., et al. (2005). Plastid DNA polymerases from higher plants, Arabidopsis thaliana. Biochem. Biophys. Res. Commun. 334, 43-50. doi: 10.1016/j.bbrc.2005.06.052

Nick McElhinny, S. A., Havener, J. M., Garcia-Diaz, M., Juarez, R., Bebenek, K., Kee, B. L., et al. (2005). A gradient of template dependence defines distinct biological roles for family $\mathrm{X}$ polymerases in nonhomologous end joining. Mol. Cell 19, 357-366. doi: 10.1016/j.molcel.2005.06.012

Ono, Y., Sakai, A., Takechi, K., Takio, S., Takusagawa, M., and Takano, H. (2007). NtPolI-likel and NtPolI-like2, bacterial DNA polymerase I homologs isolated from BY-2 cultured tobacco cells, encode DNA polymerases engaged in DNA replication in both plastids and mitochondria. Plant Cell Physiol. 48, 1679-1692. doi: 10.1093/pcp/pcm 140

Ricaud, L., Proux, C., Renou, J. P., Pichon, O., Fochesato, S., Ortet, P., et al. (2007). ATM-mediated transcriptional and developmental responses to gamma-rays in Arabidopsis. PLoS ONE 2:e430. doi: 10.1371/journal.pone.0000430

Riha, K., Watson, J. M., Parkey, J., and Shippen, D. E. (2002). Telomere length deregulation and enhanced sensitivity to genotoxic stress in Arabidopsis mutants deficient in Ku70. EMBO J. 21, 2819-2826. doi: 10.1093/emboj/21.11.2819

Roy, S., Choudhury, S. R., Sengupta, D. N., and Das, K. P. (2013). Involvement of AtPold in the repair of high salt- and DNA cross-linking agent-induced double strand breaks in Arabidopsis. Plant Physiol. 162, 1195-1210. doi: 10.1104/pp.113.219022

Roy, S., Choudhury, S. R., Singh, S. K., and Das, K. P. (2011). AtPold, a homolog of mammalian DNA polymerase $\lambda$ in Arabidopsis thaliana, is involved in the repair of UV-B induced DNA damage through the dark repair pathway. Plant Cell Physiol. 52, 448-467. doi: 10.1093/pcp/pcr002

Sakamoto, A., Lan, V. T., Hase, Y., Shikazono, N., Matsunaga, T., and Tanaka, A. (2003). Disruption of the AtREV3 gene causes hypersensitivity to ultraviolet
B light and gamma-rays in Arabidopsis: implication of the presence of a translesion synthesis mechanism in plants. Plant Cell 15, 2042-2057. doi: $10.1105 /$ tpc. 012369

Sorrell, D. A., Marchbank, A., McMahon, K., Dickinson, J. R., Rogers, H. J., and Francis, D. A. (2002). weel homologue from Arabidopsis thaliana. Planta. 215, 518-522. doi: 10.1007/s00425-002-0815-4

Stuitje, A. R., Verbree, E. C., van der Linden, K. H., Mietkiewska, E. M., Nap, J. P., and Kneppers, T. J. (2003). Seed-expressed fluorescent proteins as versatile tools for easy (co)transformation and high-throughput functional genomics in Arabidopsis. Plant Biotechnol. J. 1, 301-309. doi: 10.1046/j.14677652.2003.00028.x

Takahashi, S., Sakamoto, A., Sato, S., Kato, T., Tabata, S., and Tanaka, A. (2005). Roles of Arabidopsis AtREV1 and AtREV7 in translesion synthesis. Plant Physiol. 138, 870-881. doi: 10.1104/pp.105.060236

Tamura, K., Adachi, Y., Chiba, K., Oguchi, K., and Takahashi, H. (2002). Identification of Ku70 and Ku80 homologues in Arabidopsis thaliana: evidence for a role in the repair of DNA double-strand breaks. Plant J. 29, 771-781. doi: 10.1046/j.1365-313X.2002.01258.x

Uchiyama, Y., Hatanaka, M., Kimura, S., Ishibashi, T., Ueda, T., Sakakibara, Y., et al. (2002). Characterization of DNA polymerase $\delta$ from a higher plant, rice (Oryza sativa L.). Gene 295, 19-26. doi: 10.1016/S0378-1119(02)00822-3

Uchiyama, Y., Kimura, S., Yamamoto, T., Ishibashi, T., and Sakaguchi, K. (2004). Plant DNA polymerase $\lambda$, a DNA repair enzyme that functions in plant meristematic and meiotic tissues. Eur. J. Biochem. 271, 2799-2807. doi: 10.1111/j.1432-1033.2004.04214.x

Uchiyama, Y., Suzuki, Y., and Sakaguchi, K. (2008). Characterization of plant XRCC1 and its interaction with proliferating cell nuclear antigen. Planta 227, 1233-1241. doi: 10.1007/s00425-008-0695-3

Uchiyama, Y., Takeuchi, R., Kodera, H., and Sakaguchi, K. (2009). Distribution and roles of X-family DNA polymerases in eukaryotes. Biochimie 91, 165-170. doi: 10.1016/j.biochi.2008.07.005

Waterworth, W. M., Kozak, J., Provost, C. M., Bray, C. M., Angelis, K. J., and West, C. E. (2009). DNA ligase 1 deficient plants display severe growth defects and delayed repair of both DNA single and double strand breaks. BMC Plant Biol. 9:79. doi: 10.1186/1471-2229-9-79

West, C. E., Waterworth, W. M., Jiang, Q., and Bray, C. M. (2000). Arabidopsis DNA ligase IV is induced by gamma-irradiation and interacts with an Arabidopsis homologue of the double strand break repair protein XRCC4. Plant J. 24, 67-78. doi: 10.1046/j.1365-313x.2000.00856.x

West, C. E., Waterworth, W. M., Story, G. W., Sunderland, P. A., Jiang, Q., and Bray, C. M. (2002). Disruption of the Arabidopsis AtKu80 gene demonstrates an essential role for AtKu80 protein in efficient repair of DNA doublestrand breaks in vivo. Plant J. 31, 517-528. doi: 10.1046/j.1365-313X.2002.0 1370.x

Yokoi, M., Ito, M., Izumi, M., Miyazawa, H., Nakai, H., and Hanaoka, F. (1997). Molecular cloning of the cDNA for the catalytic subunit of plant DNA polymerase alpha and its cell-cycle dependent expression. Genes Cells 2 , 695-709. doi: 10.1046/j.1365-2443.1997.1560354.x

Yoshiyama, K., Conklin, P. A., Huefner, N. D., and Britt, A. B. (2009). Suppressor of gamma response 1 (SOG1) encodes a putative transcription factor governing multiple responses to DNA damage. Proc. Natl. Acad. Sci. U.S.A. 106, 12843-12848. doi: 10.1073/pnas.0810304106

Conflict of Interest Statement: The authors declare that the research was conducted in the absence of any commercial or financial relationships that could be construed as a potential conflict of interest.

Copyright (c) 2015 Furukawa, Angelis and Britt. This is an open-access article distributed under the terms of the Creative Commons Attribution License (CC BY). The use, distribution or reproduction in other forums is permitted, provided the original author(s) or licensor are credited and that the original publication in this journal is cited, in accordance with accepted academic practice. No use, distribution or reproduction is permitted which does not comply with these terms. 